University of South Florida

DIGITAL COMMONS

Digital Commons @ University of

@ UNIVERSITY OF SOUTH FLORIDA

South Florida

School of Geosciences Faculty and Staff

Publications

School of Geosciences

6-1997

\title{
Continuous Monitoring of Surface Deformation at Long Valley Caldera, California, with GPS
}

Timothy H. Dixon

University of Miami, thd@usf.edu

Ailin Mao

University of Miami

Marcus Bursik

State University of New York

Michael Heflin

Jet Propulsion Laboratory

John Langbein

U. S. Geological Survey, Menlo Park, CA

See next page for additional authors

Follow this and additional works at: https://digitalcommons.usf.edu/geo_facpub

Part of the Earth Sciences Commons

\section{Scholar Commons Citation}

Dixon, Timothy H.; Mao, Ailin; Bursik, Marcus; Heflin, Michael; Langbein, John; Stein, Ross; and Webb, Frank, "Continuous Monitoring of Surface Deformation at Long Valley Caldera, California, with GPS" (1997). School of Geosciences Faculty and Staff Publications. 1545.

https://digitalcommons.usf.edu/geo_facpub/1545

This Article is brought to you for free and open access by the School of Geosciences at Digital Commons @ University of South Florida. It has been accepted for inclusion in School of Geosciences Faculty and Staff Publications by an authorized administrator of Digital Commons @ University of South Florida. For more information, please contact digitalcommons@usf.edu. 


\section{Authors}

Timothy H. Dixon, Ailin Mao, Marcus Bursik, Michael Heflin, John Langbein, Ross Stein, and Frank Webb 


\title{
Continuous monitoring of surface deformation at Long Valley Caldera, California, with GPS
}

\author{
Timothy H. Dixon, ${ }^{1}$ Ailin Mao, ${ }^{1}$ Marcus Bursik, ${ }^{2}$ Michael Heflin, ${ }^{3}$ \\ John Langbein, ${ }^{4}$ Ross Stein, ${ }^{4}$ Frank Webb ${ }^{3}$
}

\begin{abstract}
Continuous Global Positioning System (GPS) measurements at Long Valley Caldera, an active volcanic region in east central California, have been made on the south side of the resurgent dome since early 1993. A site on the north side of the dome was added in late 1994. Special adaptations for autonomous operation in remote regions and enhanced vertical precision were made. The data record ongoing volcanic deformation consistent with uplift and expansion of the surface above a shallow magma chamber. Measurement precisions ( 1 standard error) for "absolute" position coordinates, i.e., relative to a global reference frame, are 3-4 $\mathrm{mm}$ (north), 5-6 mm (east), and 10-12 mm (vertical) using 24 hour solutions. Corresponding velocity uncertainties for a 12 month period are about $2 \mathrm{~mm} / \mathrm{yr}$ in the horizontal components and 3-4 mm/yr in the vertical component. High precision can also be achieved for relative position coordinates on short $(<10 \mathrm{~km})$ baselines using broadcast ephemerides and observing times as short as 3 hours, even when data are processed rapidly on site. Comparison of baseline length changes across the resurgent dome between the two GPS sites and corresponding two-color electronic distance measurements indicates similar extension rates within error ( $2 \mathrm{~mm} / \mathrm{yr})$ once we account for a random walk noise component in both systems that may reflect spurious monument motion. Both data sets suggest a pause in deformation for a 3.5 month period in mid-1995, when the extension rate across the dome decreased essentially to zero. Three dimensional positioning data from the two GPS stations suggest a depth $(5.8 \pm 1.6 \mathrm{~km})$ and location (west side of the resurgent dome) of a major inflation center, in agreement with other geodetic techniques, near the top of a magma chamber inferred from seismic data. GPS systems similar to those installed at Long Valley can provide a practical method for near real-time monitoring and hazard assessment on many active volcanoes.
\end{abstract}

\section{Introduction}

Measurement of surface deformation on active volcanoes can provide important information on magmatic processes at depth [Rundle and Whitcomb, 1984; Denlinger et al., 1985; Savage, 1988; Vasco et al., 1988; Langbein et al., 1989; Langbein et al., 1993; Dzurisin et al., 1990; Yang et al., 1992; Delaney et al., 1993; Dvorak, 1993]. Since changes in surface strain rate near active volcanoes often precede volcanic eruptions by hours to months, monitoring surface deformation also allows assessment of volcanic hazard, and in many cases has led to eruption "hindcasts" [e.g., Shimada et al., 1990; Linde et al., 1993]. Presuming rapid availability of geodetic and other data, eruption

\footnotetext{
${ }^{1}$ Rosenstiel School of Marine and Atmospheric Science, University of Miami, Florida.

${ }^{2}$ Department of Geology, State University of New York at Buffalo, New York.

${ }^{3}$ Jet Propulsion Laboratory, Pasadena, California.

${ }^{4}$ U.S. Geological Survey, Menlo Park, California.

Copyright 1997 by the American Geophysical Union.

Paper number 96JB03902.

0148-0227/97/96JB-03902\$09.00
}

forecasts and specific predictions are also possible [Thatcher, 1990]. There is some evidence that surface deformation may actually precede seismic deformation on active volcanoes by several months [Langbein et al., 1993], implying that geodesy is a critical component of any monitoring program designed to understand magmatic processes and assess volcanic hazard.

The accuracy requirements for such measurements, especially in the early stages of volcanic activity when strain rates are low, can be quite stringent. Combined with the complex spatial and temporal deformation field characterizing active volcanoes, this implies the need for high accuracy but inexpensive measurement techniques, suitable for making frequent measurements at many sites. In later stages of volcanic activity, strain rates may be much higher, permitting lower accuracy, but frequent or even continuous measurements with real-time data access become more important. Techniques requiring ground personnel may be impractical at this stage owing to hazards. To our knowledge, no currently available geodetic technique simultaneously satisfies the criteria of highaccuracy, low-cost, frequent or continuous measurement capability with real-time data access, and full automation.

Specially configured Global Positioning System (GPS) systems hold the promise of meeting most or all of these requirements in the near future. This paper describes results from a prototype system that has been operating for several years at Long Valley Caldera in California. We compare 


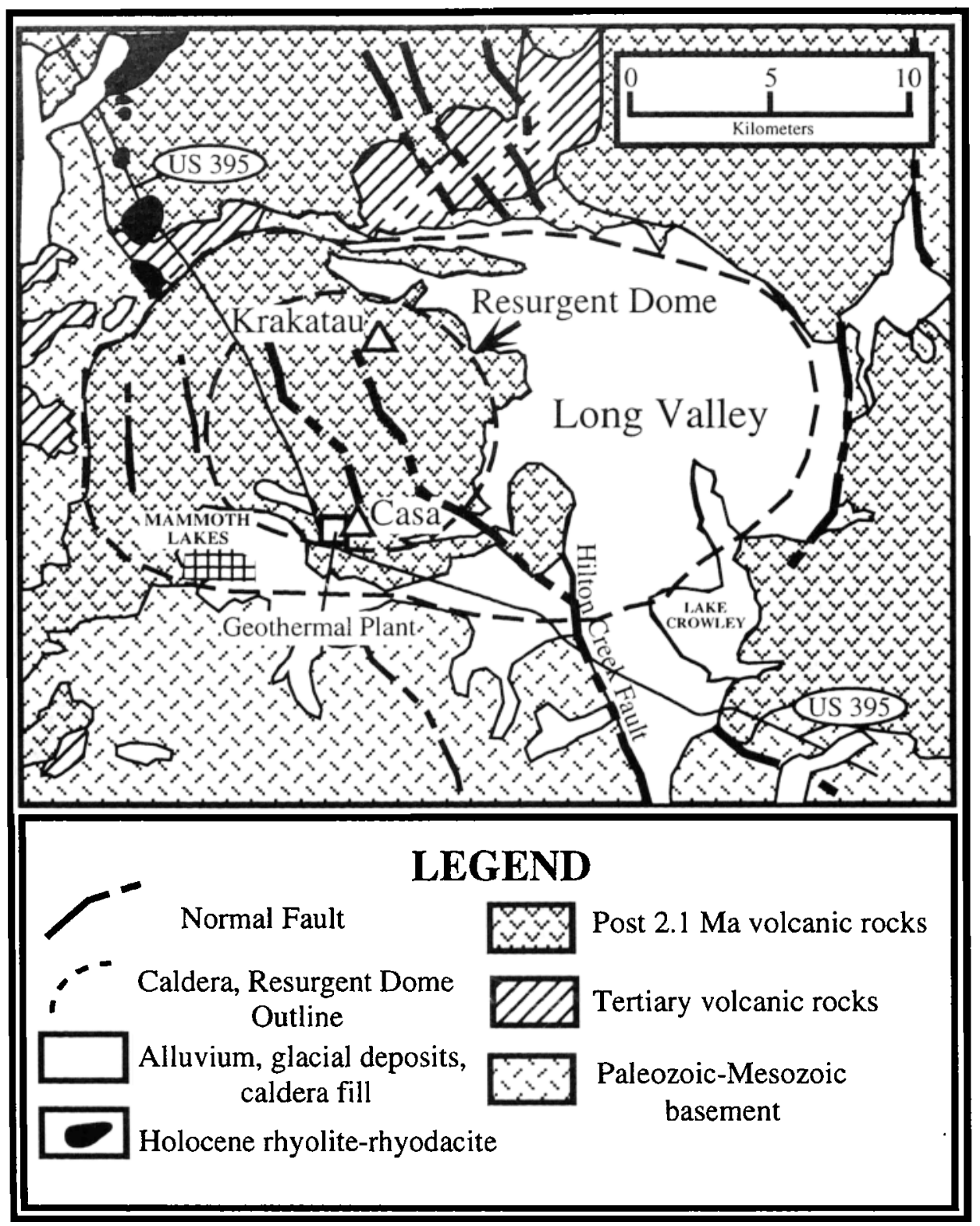

Figure 1. Geological map of Long Valley Caldera in eastern California. Note geodetic sites on central resurgent dome, abundance of young volcanic rocks in the region, and proximity of Casa Diablo power plant to CASA.

results with independent geodetic data and discuss the performance of the system, including precision, reliability, and the trade-off between precision and rapid availability of results. We also discuss solutions to problems encountered, some of which may apply to continuous GPS monitoring at other volcanoes.

\section{Data Collection Systems}

GPS has been used for several years to make highprecision geodetic measurements on active volcanoes [Dixon et al., 1993; Owen et al., 1995; Marshall et al., 1997]. These studies typically involve infrequent (e.g., yearly) observations, and rapidly varying strain signals are poorly sampled. This mode of operation also involves recurring field costs and can add noise to the measurements, especially in the vertical component, owing to repeated antenna setup on temporary tripods and the ensuing errorprone measurement of antenna height above various geodetic marks. For frequent measurements, keeping track of variable antenna height also adds a "bookkeeping" cost to the data analysis that is difficult to eliminate by automation. In highly active volcanic areas, this mode of operation also exposes ground personnel to considerable risk.

Permanent, continuously operating stations overcome all these problems and are becoming attractive for volcano monitoring as hardware costs decline and data analysis techniques become more automated. In January 1993, we began testing a permanent GPS receiver in Long Valley Caldera (Figure 1) as part of a joint NASA- U.S. Geological Survey (USGS) proof of concept program for volcano monitoring with GPS. Results from the first 15 months of operation were summarized by Webb et al. 


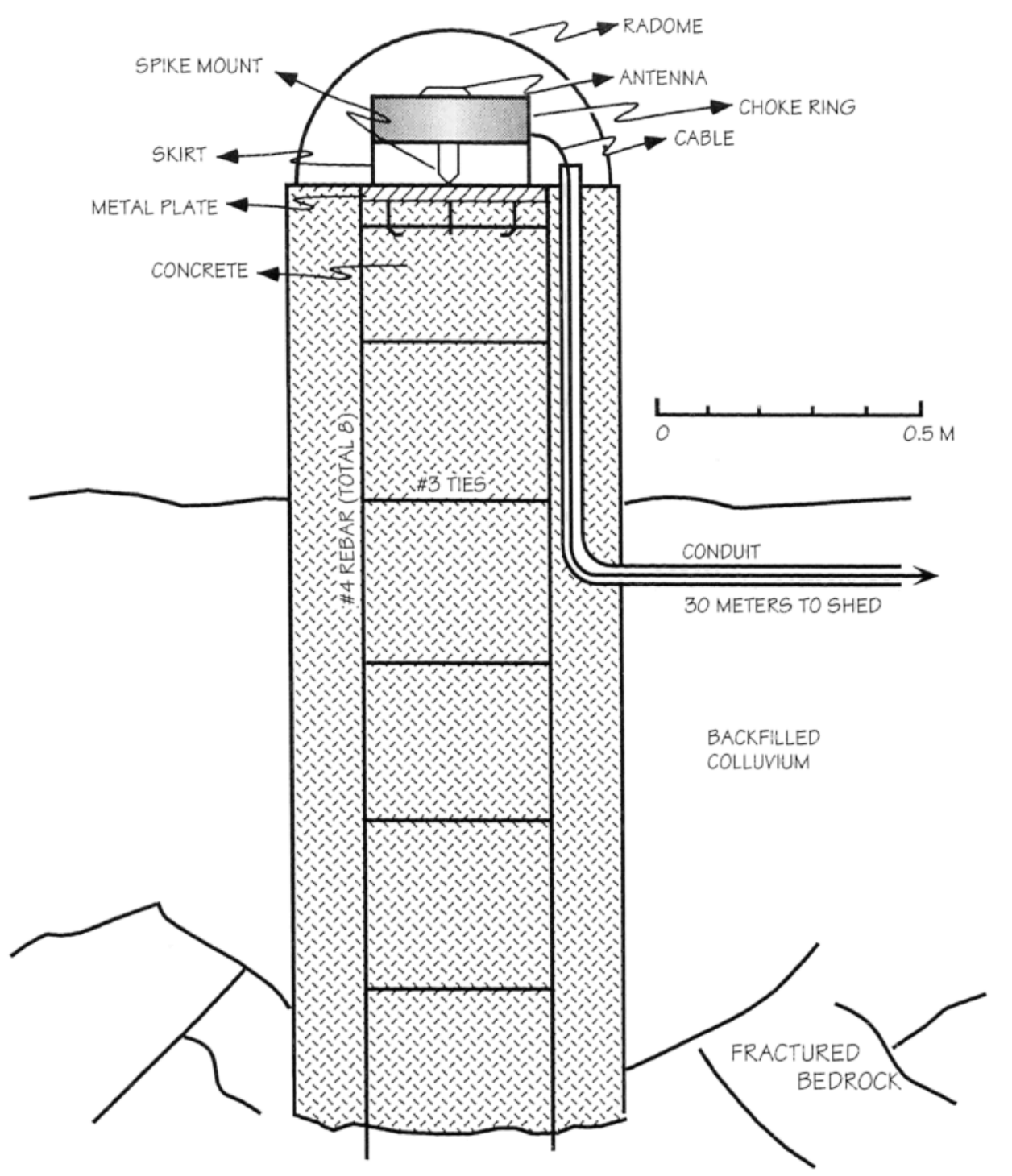

Figure 2 . Scale drawing of GPS monument and antenna/choke ring at CASA. The concrete pillar is cored with eight number 4 steel rebar (two indicated on drawing).

[1995]. Following a 3 month period in early 1993, when the antenna was covered by deep snow, the system has performed well, providing a nearly continuous record of three-dimensional surface displacement.

This first station was installed near the USGS highprecision two-color electronic distance measurement (EDM) facility "CASA," named for nearby Casa Diablo hot springs. The site is several kilometers south of the center of the resurgent dome (Figure 1), the area of most active deformation within the caldera. The CASA site has the benefits of large deformation signal, available facilities (power and a small building to house the receiver), and most importantly proximity to an independent instrument for data comparison. The two-color instrument is the most precise distance measuring device in the world for baseline distances of 1 to $10 \mathrm{~km}$, affording an unprecedented opportunity for rigorous calibration of the GPS technique for deformation monitoring under realistic conditions.

To facilitate this calibration, we installed a second GPS site (KRAKATAU, Figure 1) $8 \mathrm{~km}$ north of CASA on the north side of the resurgent dome in October 1994, close to the EDM reflector of the same name, allowing direct comparison between GPS and two-color EDM data. This report emphasizes the post-October 1994 period when both stations were operational.

Both the CASA and KRAKATAU GPS sites are equipped with identical TurboRogue receivers and DornMargolin antennas with "choke ring" backplanes for multipath suppression, manufactured by Allan Osborne Associates. The receivers are dual-frequency systems capable of tracking up to eight satellites simultaneously, and record both $P$ code and carrier phase data at $30 \mathrm{~s}$ intervals. The CASA site design is similar to many other International Geodynamic Service (IGS) tracking sites installed about this time. It is monumented with a wide, concrete pillar ( $\sim 0.6 \mathrm{~m}$ diameter) cored with eight steel reinforcing rods and extending from a depth of about $1.5 \mathrm{~m}$ below the surface to about $0.6 \mathrm{~m}$ above the surface (Figure 2). Excavation of the site prior to monument installation indicated large, highly fractured rhyolitic blocks and colluvial material but no clear bedrock within $1.5 \mathrm{~m}$ of the surface. The pillar is not isolated from the backfilled 


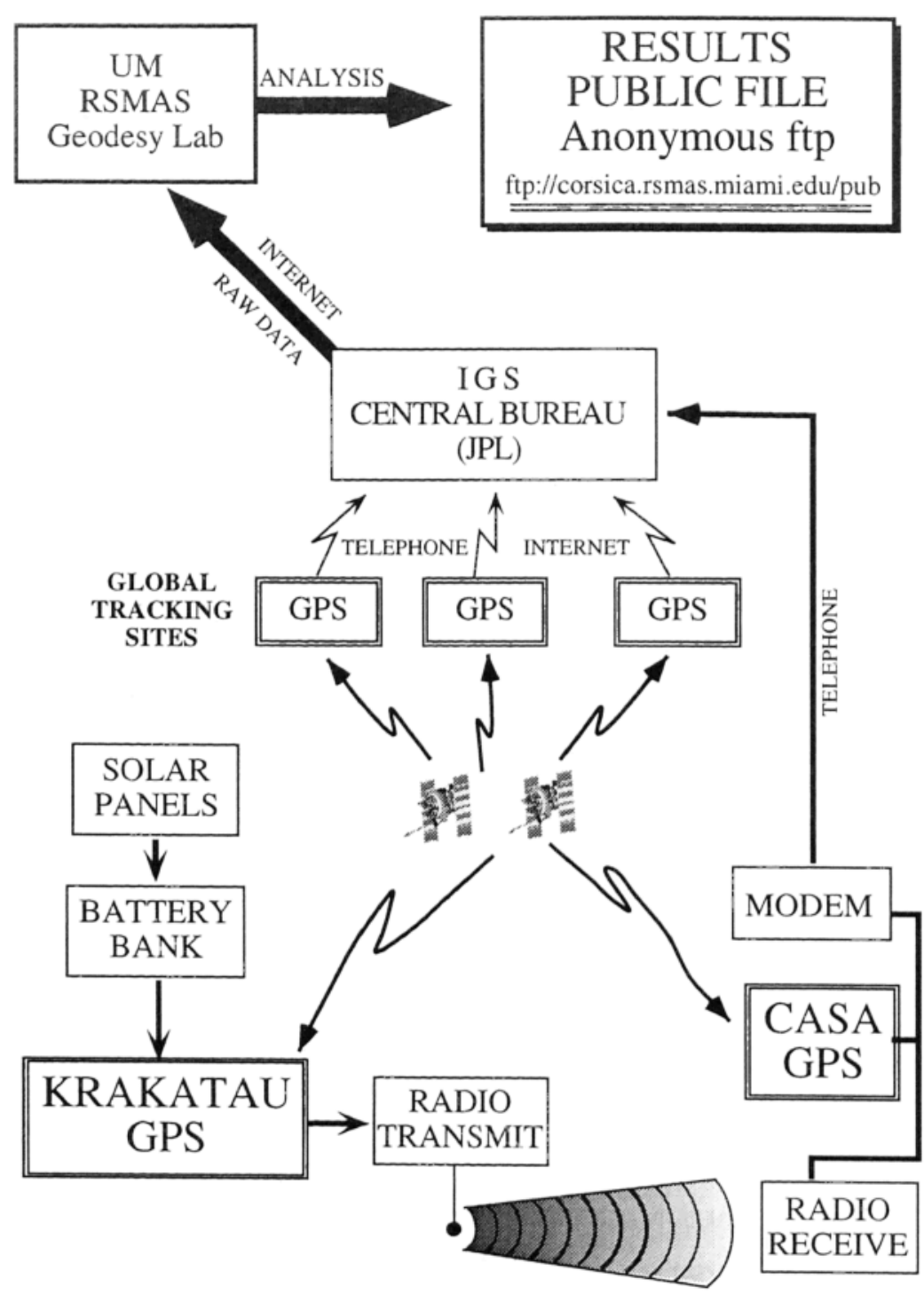

Figure 3. Cartoon of GPS data acquisition, transmission, and analysis system for the permanent GPS sites CASA and KRAKATAU in Long Valley Caldera.

colluvium, although its large mass $(\sim 1500 \mathrm{~kg})$ may reduce spurious monument motion associated with wet/dry and freeze/thaw cycles in the near surface. The antenna is mounted on a spike, sits approximately $10 \mathrm{~cm}$ above the surface of the pillar, and is covered by a plastic dome ("radome," Figure 2). The KRAKATAU site is monumented with a stainless steel pin $1 \mathrm{~cm}$ wide by $16 \mathrm{~cm}$ long set in a large rock which we believe to be bedrock. The antenna is mounted on a spike a similar distance $(\sim 10$ $\mathrm{cm}$ ) above the uneven bedrock surface.

The CASA receiver has AC power available but uses a battery interface to span brief power interruptions. Raw data are transmitted via modem and telephone line to the IGS Central Bureau computer at the Jet Propulsion Laboratory (JPL), where they are made available to researchers on the Internet via anonymous ftp (file transfer protocol). The KRAKATAU receiver is more remote and is powered by solar panels which charge batteries, enabling this receiver to run for several days during overcast weather. Longer periods of bad weather result in loss of power, and the system is designed to power down and up automatically depending on power availability. The data are transmitted via radio modem to the CASA site for incorporation into the modem/telephone/Internet data stream, a design similar to one developed by the USGS for monitoring Augustine volcano in Alaska [Murray et al., 1992]. Major elements of the data collection and transmission system are outlined in Figure 3.

The receiver/antenna system at KRAKATAU has remained essentially constant since its installation in October 1994. In contrast, the system at CASA went through a number of minor changes in its first 1.5 years of operation, including installation of an external heater, replacement of a faulty receiver clock, and installation of new operating system firmware. With two exceptions noted below, its configuration has remained constant since October 1994.

Research at other IGS tracking sites has indicated that the "standard" IGS pillar antenna mount of this era, where the antenna and its choke ring back plane are mounted on a 
short spike about $10 \mathrm{~cm}$ ( one half carrier wavelength) above a metal centering plate (Figure 2), can lead to large amounts of multipath and vertical variations in the phase center that are elevation-angle-dependent [Niell et al., 1994]. These problems may be related to signal resonance phenomena between the base of the choke ring and the metal centering plate. The CASA site employs this design, and thus its data are similarly affected. As with any elevation-angle-dependent phenomenon, this can adversely affect the vertical component, important for volcano monitoring. Since we use a constant elevation-angle cutoff $\left(15^{\circ}\right)$ in our analyses, systematic error associated with phase center variation should be small. However, random and possibly systematic error associated with multipath may be present. To reduce this, we departed from the standard configuration and added a thin metal "skirt" around the base of the choke ring on May 26, 1995. The date of this addition is noted on the relevant figures. At about the same time (June 3, 1995), the firmware that controls receiver operation and data collection was upgraded from version 3.0 to version 3.2 .

\section{Data Analysis}

The GPS data from CASA and KRAKATAU are publicly available from the IGS, and many groups participate in the analysis. Several of these groups also analyze data from a global network of GPS stations, producing precise satellite ephemerides and in, some cases, satellite clock files, that can be used to reduce GPS data processing time for other stations. The satellite ephemerides from these centers are submitted to the IGS, where they are averaged and made available 1-2 weeks after data collection.

Here we report results analyzed with the GIPSY software [Zumberge et al., 1997] at the University of Miami (UM). The GPS time series discussed here were generated in one of three ways, as part of a dedicated volcano monitoring program that began at $\mathrm{UM}$ in mid1994. First, UM analyzes data from many of the same stations as other IGS analysis centers, typically 30 or more globally distributed stations, plus other stations not analyzed by these centers. Many of the additional stations are located on active volcanoes and have somewhat less stringent configuration control compared to a permanent IGS station. For example, they may not be permanent, or continuous data may not be available, or they may not report results on a daily basis; data from some stations arrive up to 1 month after collection. These time series use precise satellite ephemerides and clock files generated by $\mathrm{JPL}$, and are termed "UM/Precise Orbits and Clocks," (UM/POC). Unless specifically noted, they are used in all the figures and discussion in this paper.

The second time series reflect the need to generate precise surface displacement data in near real-time for volcano hazard monitoring. These time series are based on analysis of a global network of approximately 20 tracking sites plus any volcano stations with rapid data transmission capability. Satellite orbits, satellite and station clocks, and station positions are estimated simultaneously at UM within 24 hours of data reception, and results are made available to scientists and public officials via anonymous ftp (ftp://corsica.rsmas.miami.edu/pub; see Dixon et al.
[1995]), typically within 36 hours of data reception. We refer to these time series as "UM/Quick Look." The UM/Quick Look time series have somewhat lower precision compared with the first time series, depending mainly on how many tracking stations are available and are used for orbit estimation. Figure 4 compares KRAKATAU data from the UM/POC and UM/Quick Look time series for a typical 6 month period. Most solutions agree within formal errors, and the velocities are equivalent at $95 \%$ confidence. The weighted root mean square (wrms) scatter of the two time series about the best fit line, one measure of precision, differs by no more than a few millimeters. The differences between the solutions are small compared to the potentially large surface strain signals on an active volcano.

We also present limited data from a third time series spanning just 8 days that employs broadcast ephemerides and compares several different sampling schemes. These time series are designed to investigate the feasibility of essentially real-time, on-site data analysis with time resolution of several hours, a capability that may be useful in a volcanic emergency.

Data analysis procedures for these three time series are described in the appendix. Unless noted, in all time series the data outliers, defined as lying more than 5 standard deviations from the best fit line, are flagged but not removed and the user has the option of incorporating them in the velocity fit. This philosophy reflects the difficulty of distinguishing signal from noise in near real-time when the signal (volcanic deformation) may be highly variable in time.

\section{Results and Discussion}

The daily position data for CASA and KRAKATAU (UM/POC time series) are shown in Figure 5. Data gaps at KRAKATAU represent periods of heavy snow which covered the solar panels (January 3 to February 2, 1995), and battery failure associated with cold weather (March 8 to April 22, 1995), perhaps related to the earlier period of low or no battery charging. Except for those outages, both systems have performed reliably.

The plotted positions represent daily geographical coordinate solutions in the 1994 International Terrestrial Reference Frame(ITRF-94) [Boucher et al., 1996]. In this reference frame the vertical velocities can be considered to be relative to the center of mass of the earth, while the horizontal velocities are related to the NUVEL-1A no net rotation (NNR) reference frame [Argus and Gordon, 1991; DeMets et al., 1994]. Averaged over the entire period, both sites show continuing uplift. The horizontal coordinate velocities are dominated by motion of the North American plate relative to the reference frame. Horizontal velocities relative to the adjacent stable Sierra Nevada block, more useful for assessing local volcanic deformation, are discussed later.

The velocities and corresponding errors are defined by a weighted least squares line fit through the daily position data for a given period (unless specifically noted, all uncertainties are quoted at 1 standard error). In the case of Figure 5, we calculated an average velocity and error over the entire 2.5 year (CASA) or 2.0 year (KRAKATAU) period. The velocity error assumes a simple white 


\section{KRAK Geographical Coordinates}

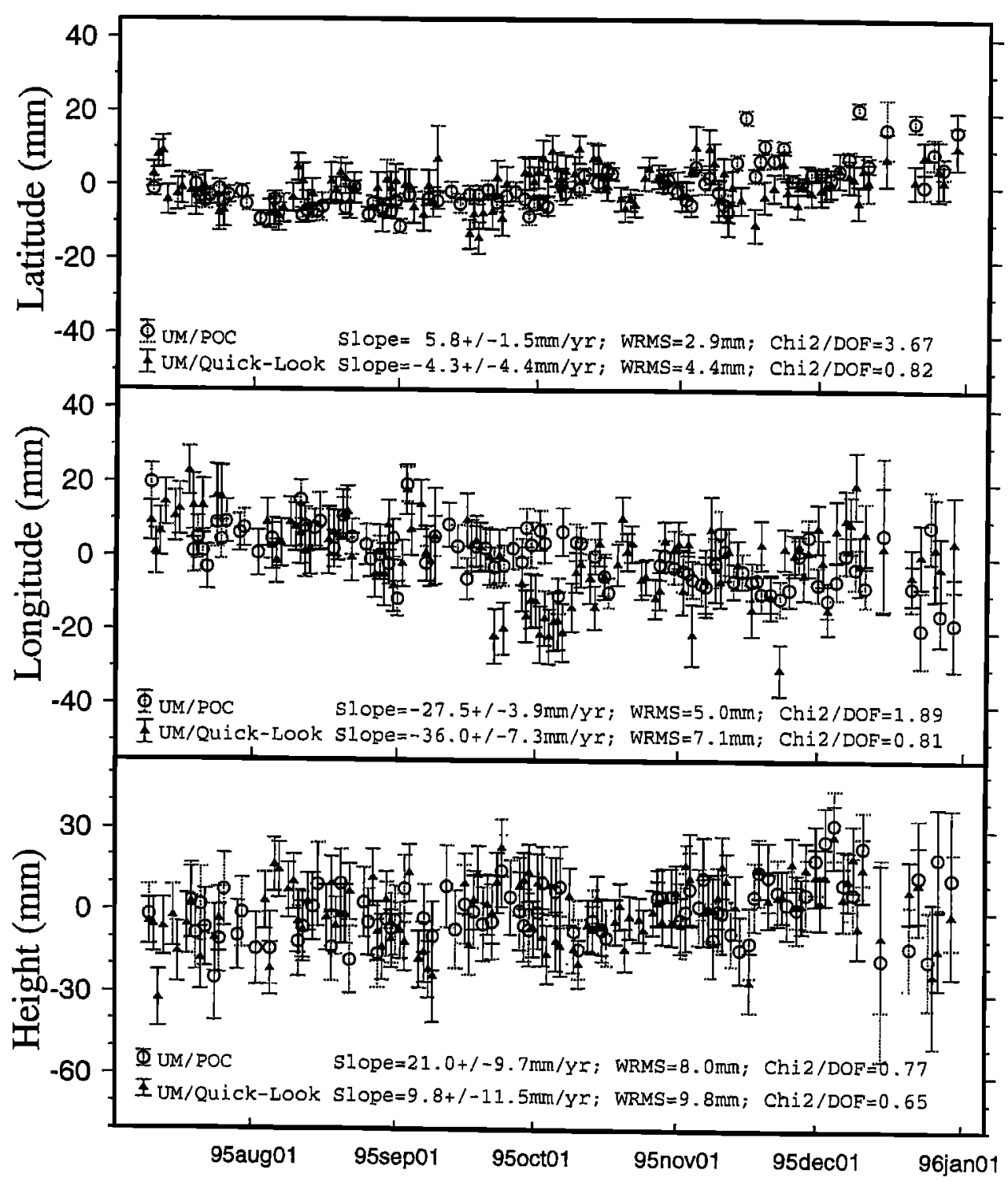

Figure 4. Comparison of University of Miami/Precision Orbits and Clocks (UM/POC) solutions and UM/Quick Look solutions for KRAKATAU GPS site for July-December 1995. The weighted root mean square (wrms) scatter of the Quick Look solutions about a best fit line differs by no more than $3 \mathrm{~mm}$ from the POC solutions for all components, and the velocities are equivalent at the $95 \%$ confidence limit (2 times standard error).

(uncorrelated) noise model. The wrms scatter about the line gives an estimate of the average precision of a daily measurement, again assuming white noise. Precisions are approximately 3-4 $\mathrm{mm}$ (north), 5-6 $\mathrm{mm}$ (east), and 10-12 $\mathrm{mm}$ (vertical), typical of performance at many other IGS sites in more benign environments. The velocity errors depend on the daily precisions, the number of measurements, the total time span of observations, and the nature of other noise sources. The velocity errors for 1 year of observation assuming only white noise are less than $2 \mathrm{~mm} / \mathrm{yr}$ for each horizontal component and $\sim 3 \mathrm{~mm} / \mathrm{yr}$ for the vertical component. Incorporating correlated noise into the error analysis will increase the velocity error estimates, depending on the magnitude of the correlated noise and the time span involved. In a later section we explicitly address monument noise, which may be a type of correlated noise.

Note the decrease in scatter at CASA after May 26, 1995, when the antenna skirt was installed. Wrms scatter for the vertical component decreased by about a factor of 2 , from $15.1 \mathrm{~mm}$ before skirt instalation to $7.3 \mathrm{~mm}$ after. Horizontal components were much less affected and the changes may not be significant, from 3.3 to $2.9 \mathrm{~mm}$ in the north component and from 6.0 to $5.2 \mathrm{~mm}$ in the east component. Although receiver firmware was upgraded at about the same time, inspection of data from other IGS sites that underwent the same upgrade in 1995 but with no antenna change suggests no significant effects due to the 


\section{CASA Geographical Coordinates}

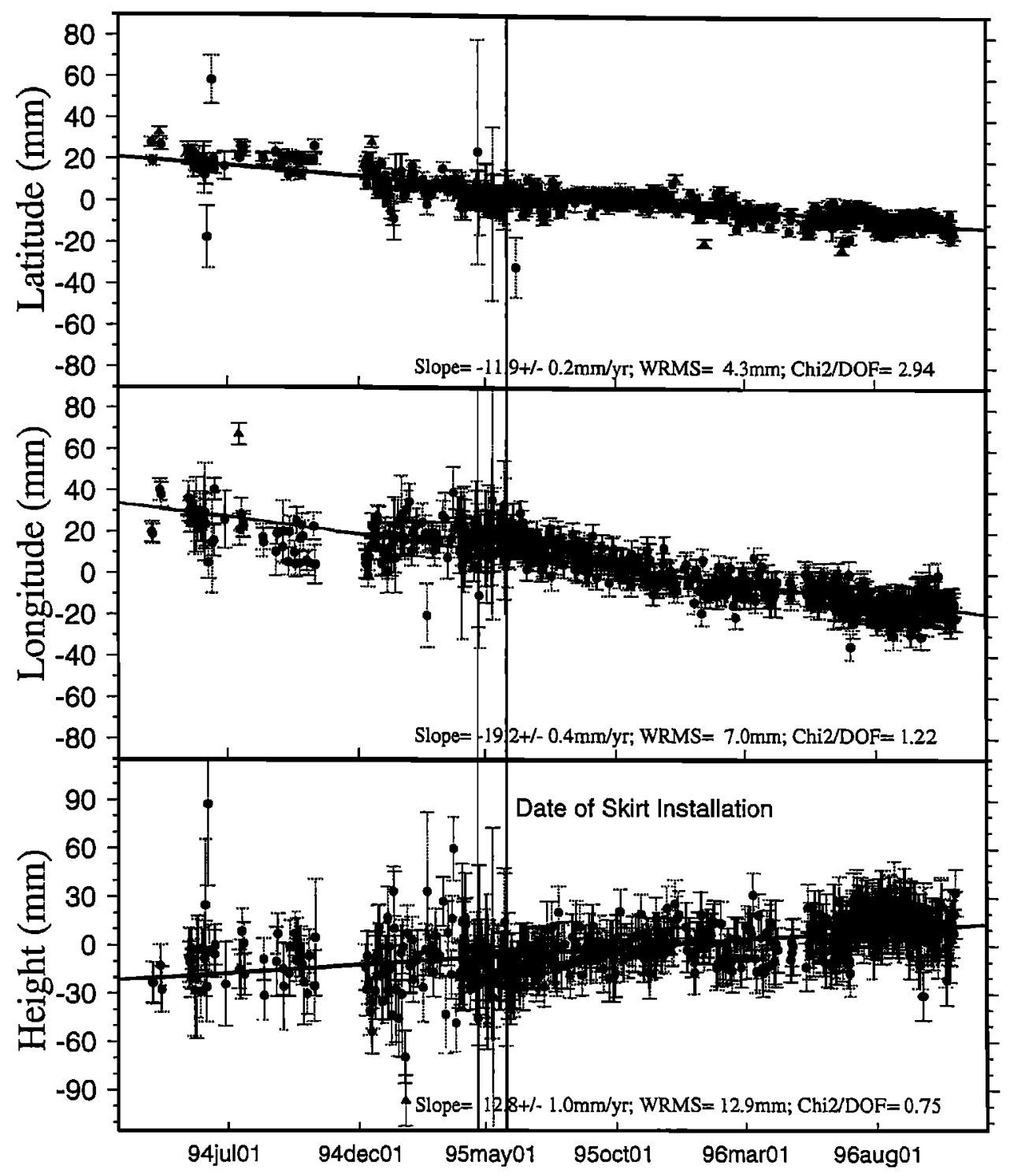

Figure 5. Motion of (a) CASA and (b) KRAKATAU in ITRF-94 reference frame up to to November 1 , 1996 (UM/POC solution-see text). Vertical line in Figure 5a shows time of installation of metal skirt at base of CASA antenna to reduce multipath.

firmware upgrade. For example, for the IGS station Algonquin Park, Ontario (ALGO) the wmms scatters in north, east, and vertical components for 1 year before (first value) and 1 year after (second value) the firmware upgrade are 3.1 and $3.2 \mathrm{~mm}, 4.2$ and $4.6 \mathrm{~mm}$, and 9.4 and $9.7 \mathrm{~mm}$, respectively. For the station at Pietown, New Mexico (PIE1), the corresponding values are 3.4 and $3.1 \mathrm{~mm}, 6.5$ and $6.1 \mathrm{~mm}$, and 11.8 and $9.5 \mathrm{~mm}$. Thus the improvement in data quality at CASA after May 26, 1995, likely reflects only the addition of the skirt and not the firmware upgrade. The offset in the vertical component associated with the addition of the skirt was less than 1 $\mathrm{mm}$ and not statistically significant. We conclude that addition of an antenna skirt improves vertical data quality at IGS sites with pillar-type monuments and metal centering plates.

\section{Real-Time Results}

The near real-time aspect of the UM/Quick Look results, typically available 24-48 hours after the end of the 24 hour data collection period, enhances their utility for volcano hazard assessment. However, in the event of an emergency, a delay of even 1 day between data collection and availability of results would be a liability. Also, 24 hour averages may alias a rapidly changing deformation signal for a volcano approaching eruption.

In principle, data from our stations can be transmitted to UM or any other processing facility at arbitrarily short intervals and, of course, are available on site at these intervals as well. However, it is impractical to obtain data from other global tracking stations at these same intervals in order to perform simultaneous estimation of satellite 


\section{KRAK Geographical Coordinates}

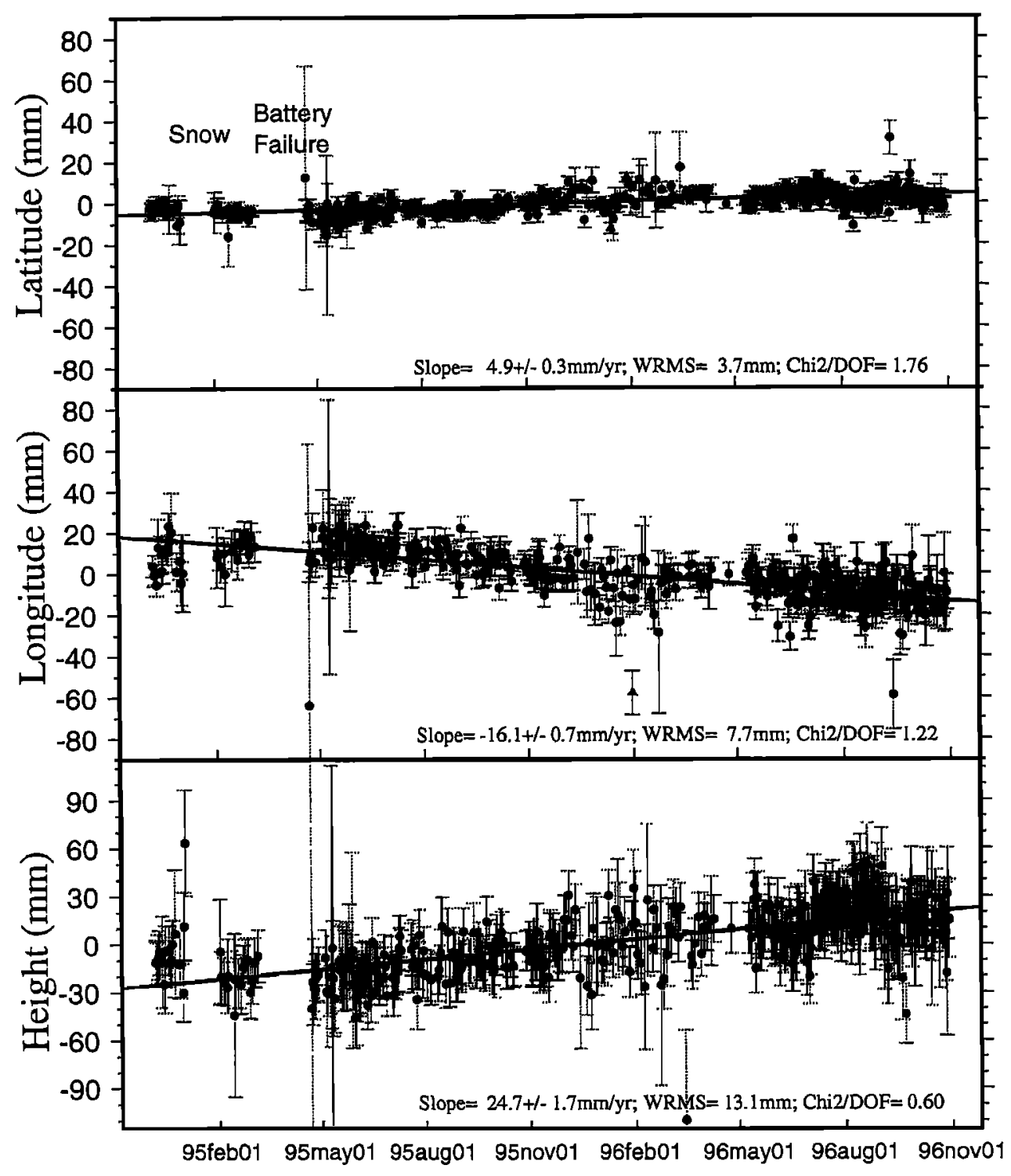

Figure 5. (continued)

orbits and station positions. Also, this approach implies continued availability of a sophisticated communication system such as modem/telephone or Internet connections for transmission of raw data from the site and subsequent dissemination of results back to the site.

There are two ways to produce results with time delay less than 1 day, each with some sacrifice in precision. First, we could predict satellite ephemerides several days in the future given current ephemerides and knowledge of major forces affecting satellite orbits, mainly Earth's gravity and solar radiation pressure. Several groups produce orbit predictions, and their accuracy is steadily improving. However, this approach still requires sophisticated communications, either to the site for dissemination of orbit predictions or away from the site for dissemination of raw data to a central processing facility, and the necessary infrastructure may not be available in an emergency. It is therefore desirable to have a "selfcontained" processing system that can produce rapid but reasonably precise results on or near the volcano, independent of outside communications. The second approach addresses this need and employs broadcast ephemerides contained in the GPS satellite signal recorded by the ground receivers. It is thus independent of ground communications to or from the site.

To investigate the degradation in accuracy associated with using broadcast ephemerides and with using time averages shorter than 24 hours, we computed results for the $7.7 \mathrm{~km}$ CASA-KRAKATAU baseline for a typical 8 day period using broadcast ephemerides for the standard 24 hour period, as well as 6 hour, 3 hour, and 2 hour averages. The 24 hour and 3 hour solutions were computed with both the broadcast ephemerides and with the precise orbit and clock information (UM/POC solution). Solutions using broadcast ephemerides were generally similar to those based on the precise orbit and clock information within formal errors, reflecting lack of sensitivity to the quality of orbit information on this short baseline. Figure 6 shows the 24 


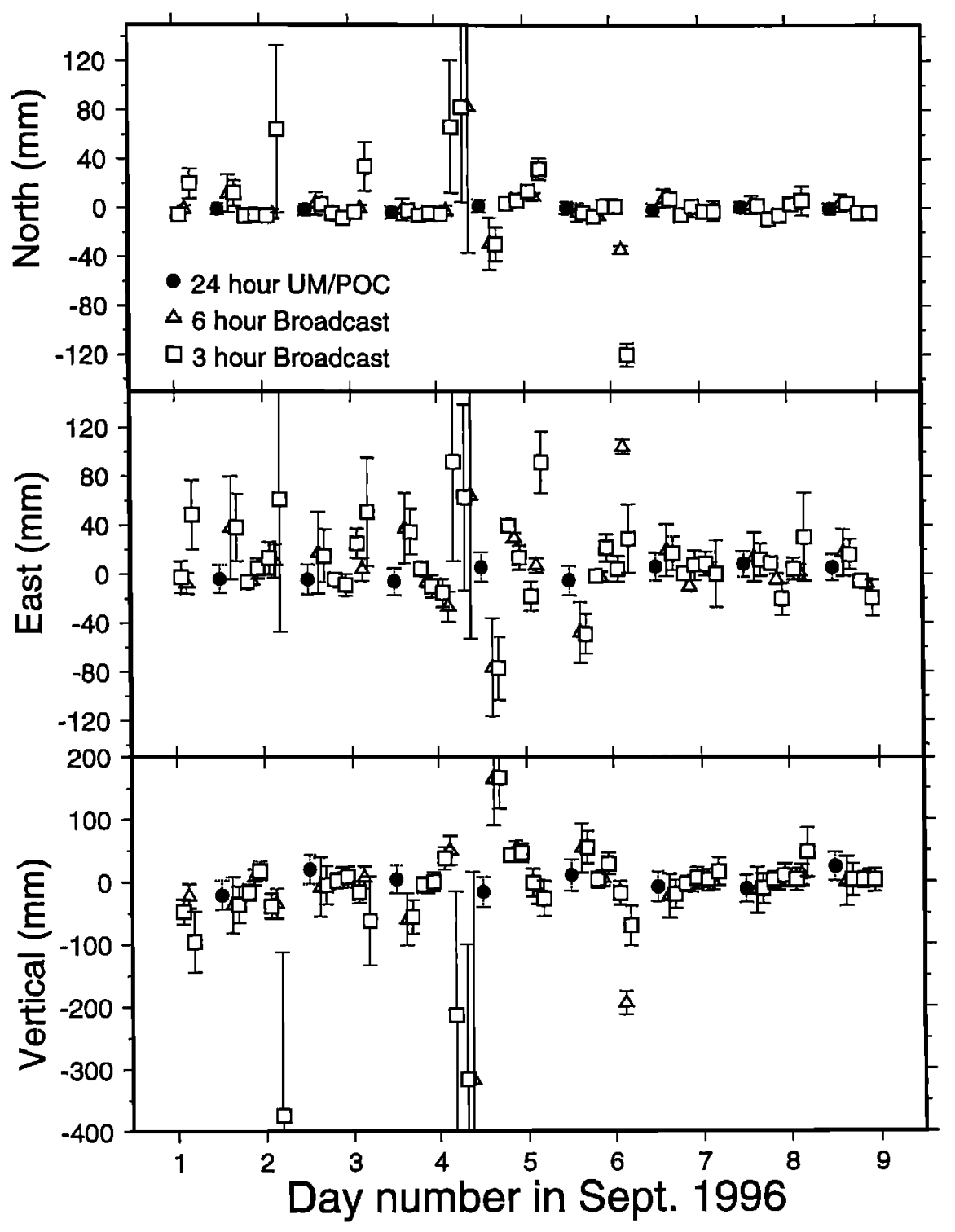

Figure 6. North, east, and vertical relative baseline coordinates between CASA and KRAKATAU using the broadcast ephemeris for 6 hour and 3 hour solutions compared to 24 hour solutions using precise ephemeris and clock information ("24 hour UM/POC"). Data gaps represent power loss at KRAKATAU.

hour UM/POC solution for comparison to the 6 and 3 hour solutions based on broadcast ephemerides. During this period, the KRAKATAU site was off for 7-9 hours per day during local night and early morning owing to lack of power. This eliminated several 2 and 3 hour sessions and one 6 hour session per day, and caused weak solutions with large formal errors when an adjacent data session was incomplete. The mean values of the 6 and 3 hour results are consistent with the 24 hour result within formal errors, indicating no systematic offset associated with using the shorter time averages or broadcast ephemerides. Solutions with time averages shorter than 24 hours exhibited more scatter than the 24 hour solution, but no more than expected from formal errors. For example, the 24 hour UM/POC solution has wrms scatter for north, east, and vertical components of $1.7 \mathrm{~mm}, 4.5 \mathrm{~mm}$, and $17.7 \mathrm{~mm}$ respectively. For the 3 hour broadcast ephemerides solutions, the corresponding values are $29 \mathrm{~mm}, 32 \mathrm{~mm}$, and $88 \mathrm{~mm}$. The degradation of data quality associated with shorter time averages would depend on location and satellite geometry at the time of observation, but these results are probably typical.

Our results using broadcast ephemerides were computed on a Sun Sparc 5 work station, used no additional station data (that is, only data from CASA and KRAKATAU were used), and required only several minutes of computer processing time. We conclude that the use of several hour time averages with broadcast ephemerides is viable for monitoring volcanic deformation with a precision of several centimeters in relative coordinates for short baselines. Data can be processed on site without external communications, and results can be made available in essentially real-time. Short baseline radio communication within the volcanic region is still required to access data 
from remote sites, but this can be accomplished with radio modems and repeaters similar to units we employ at Long Valley. Several commercial software packages are available that perform these baseline computations on portable computers, consequently these results should be applicable to any volcano monitoring program.

\section{EDM Comparison and Monument Stability}

The best way to assess a geodetic technique is to compare results to independent data. The GPS-determined rate of change of length between CASA and KRAKATAU can be compared with high-precision two-color electronic distance measurements (EDM) [Langbein et al., 1993; 1995b]. Two-color EDM are obtained from monuments that are within a few tens of meters of the GPS monuments. Two-color EDM measures the travel time of light using two wavelengths, rod and blue, and uses the difference in travel time to compensate for the density of the atmosphere, which affects the refractive index and travel time. Distances are measured with a precision of 0.1 parts per million (ppm) [Slater and Huggett, 1976]. This is a factor of 2 to 10 better than single-color techniques [Savage and Prescott, 1973] and, for the distance range of about 1$10 \mathrm{~km}$, also better than GPS. In fact, it is the most precise technique available for measurement of distance and displacement over this length scale. The availability of both GPS and two-color EDM, each with high time resolution and spanning a 2 year period, allows a rigorous comparison of these techniques and evaluation of errors.
Figure 7 shows all available daily length estimates from the UM/POC analysis between the CASA and KRAKATAU GPS monuments, compared to two-color EDM data for the equivalent EDM monuments for the same period. Barring power interruptions, the GPS data are collected daily, and represent 24 hour means. The laser results are typically collected 2-4 times per week, sometimes less in poor weather. To correct for these and other sampling differences, we calculated 5 day weighted means for each data set using the same data editing procedures on both data sets to remove outliers and points with large formal errors (Figure 8).

In principle, we could compare GPS and two-color EDM in terms of accuracy, precision, and the ability to detect deformation over limited time periods. Because we use a different set of benchmark pairs for the two systems, we cannot rigorously assess the accuracy of one instrument relative to the other without additional data. On the other hand, since the benchmarks are close to each other and of similar design, it is reasonable to expect that each system measures essentialy the same deformation field and experiences a similar level of "monument noise," spurious ground motion unrelated to the volcanic signal of interest. Monument motion due to local, shallow ground processes has been identified as a potentially important noise source in a number of recent geodetic studies [Wyatt, 1989; Johnson and Agnew, 1995; Langbein et al., 1995a; Langbein and Johnson, 1997]. While there are designs that minimize the problem by anchoring to deep earth and isolating the monument from motion of the top several

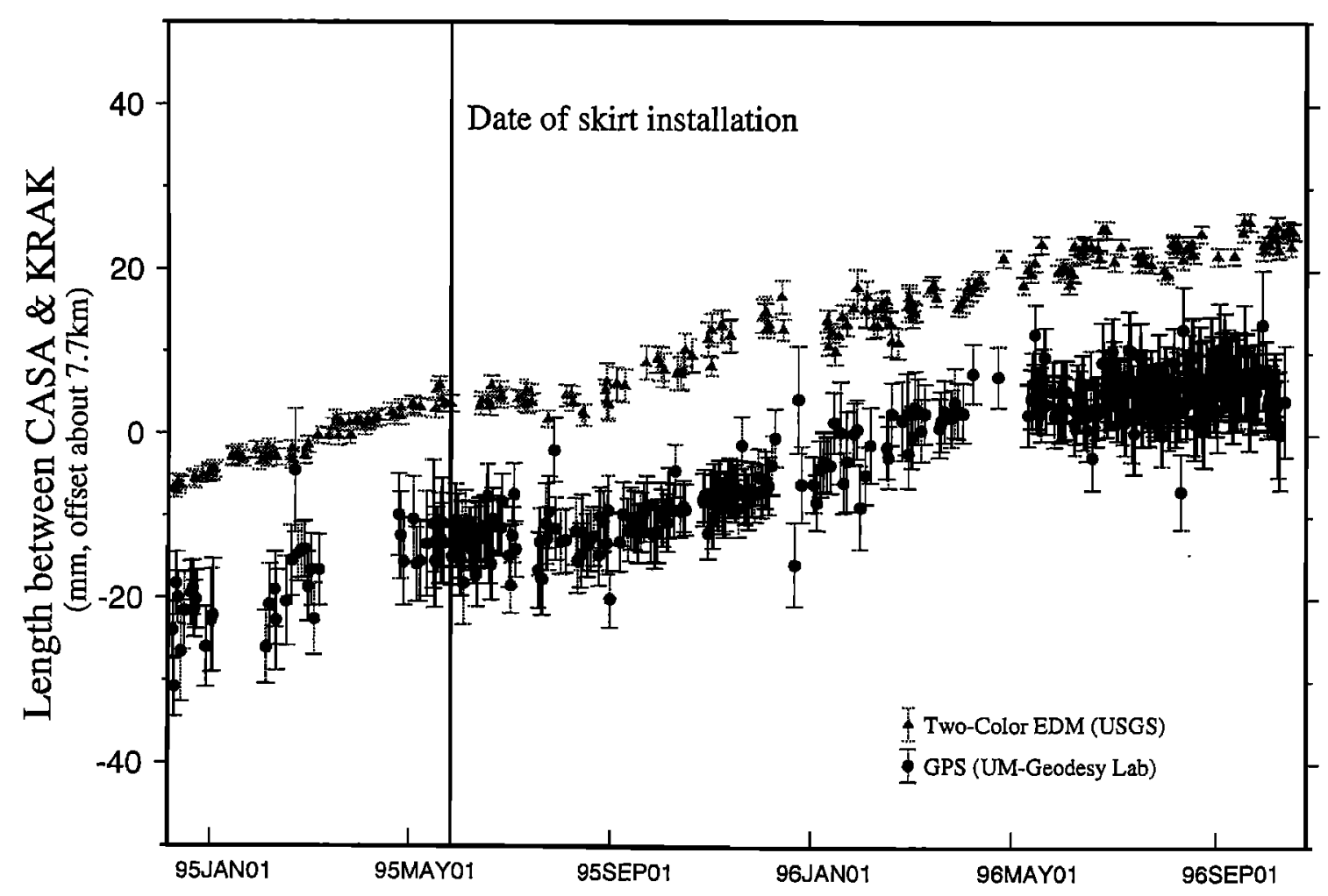

Figure 7. Comparison of length estimates between CASA and KRAKATAU from two-color EDM (triangles) [Langbein et al., 1995] and daily GPS UM/POC solution (circles), with arbitrary starting positions. Stippled vertical lines are 1 standard deviation for each measurement. All available GPS data including outliers have been plotted. Note apparent slowdown in rate of expansion between early May and late August 1995 observed in both systems. 


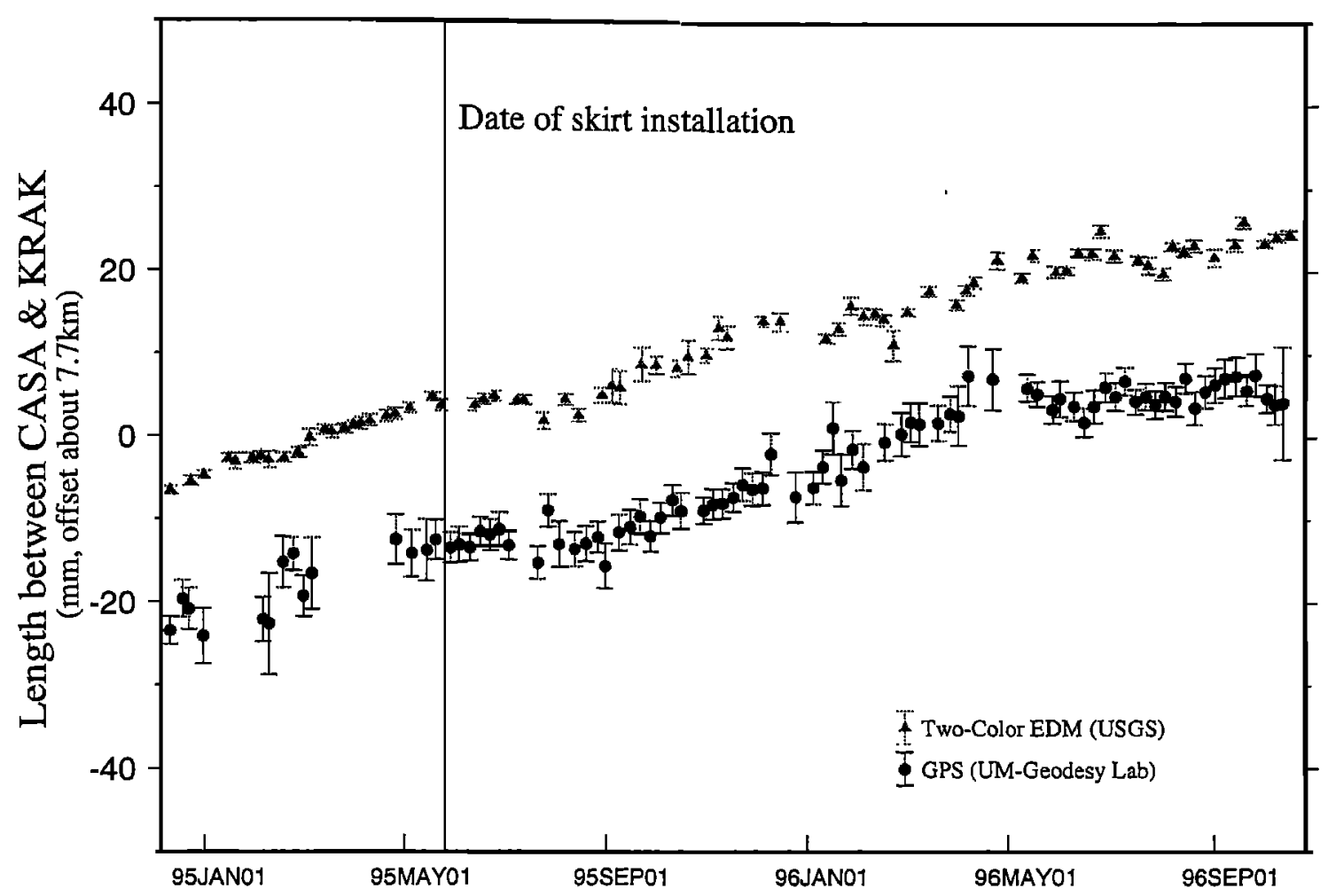

Figure 8. Similar to Figure 7 but applying similar editing schemes to each data set and comparing 5 day means weighted by formal errors.

meters of soil [Langbein et al., 1995b], their cost is prohibitive for some applications and their installation is not practical on many volcanoes. Thus monument noise may be a critical factor limiting the accuracy of longer term surface deformation measurements on volcanoes, which can experience extreme annual or even diurnal temperature fluctuations and frequent freeze/thaw cycles in the upper soil horizons. Comparison of GPS and two-color EDM may allow us to distinguish common (e.g., monument) and independent noise sources and quantify the monument effects.

The precision or repeatability of the measurements can be addressed following Langbein and Johnson [1997]. These authors characterized measurement repeatability in terms of white (Gaussian) noise and random walk (colored, Brownian, or time correlated) noise. They assumed that white noise is associated with the instrumental technique and that random walk noise is associated with spurious monument motion. Given the short GPS time series and our lack of understanding of the GPS error spectrum, other noise sources (e.g., unmodeled atmospheric effects) might also have the properties of a random walk and might be difficult to separate from monument noise without reference to larger data set, beyond the scope of this study. While our data are insufficient to prove that monument noise is a random walk process or that all random walk behavior in a GPS time series is exclusively due to monument noise, this model provides a reasonable framework for our discussion and is assumed below.

In their analysis of many geodetic baselines, Langbein and Johnson [1997] included 11 years of two-color EDM data from Long Valley. Given the low white noise of the two-color instrument, these time series are long enough to distinguish white and random walk noise and long enough to separate seasonal and random walk effects. After subtracting an annual term and a time-dependent deformation model, curves were fit to residuals to assess white and random walk errors. For the CASAKRAKATAU baseline, the white noise component in the EDM data is $1.0 \pm 0.06 \mathrm{~mm}$ and the random walk component is $2.5 \pm 0.3 \mathrm{~mm} / \sqrt{\mathrm{yr}}$, with the latter number reflecting the addition in quadrature of the noise effect of two monuments at each end of the baseline. The corresponding value for a single monument is $1.8 \mathrm{~mm} / \sqrt{\mathrm{yr}}$. Inspection of the entire data set suggests a weakly defined baseline length dependence, with the random walk noise for a "zero length" baseline $=1.3 \mathrm{~mm} / \sqrt{\mathrm{yr}}(0.9 \mathrm{~mm} / \sqrt{ } \mathrm{yr}$ for a single monument). To be conservative, we ignore this length dependence and assume that all of the random walk noise observed in the EDM data is due to monument motion and thus may apply to the GPS data as well.

Before applying the technique of Langbein and Johnson [1997], we edited the GPS data in a fashion comparable to the two-color EDM, deleting nine outliers and removing measurements that had formal errors greater than $8 \mathrm{~mm}$. If we ignore annual effects, the error analysis indicates that the GPS data have a white noise component of $2.9 \pm 0.1$ $\mathrm{mm}$ and a random walk component of $4.7 \pm 1.1 \mathrm{~mm} / / \mathrm{yr}$. However, if we instead assume that annual periodic noise is present, we obtain a $2.4 \mathrm{~mm}$ amplitude annual signal and a white noise component of $3.0 \pm 0.1 \mathrm{~mm}$, while the apparent random walk component is reduced to zero. With only 2 years of GPS data, it is not possible to separate the annual component from the random walk component with 
Table 1. Comparison of Secular Rate Between GPS and Two-Color EDM

\begin{tabular}{lrr}
\hline \multirow{2}{*}{ Period } & \multicolumn{2}{c}{ Rate, mm/yr } \\
\cline { 2 - 3 } & \multicolumn{1}{c}{ GPS } & 2-Color EDM \\
\hline Oct. 1, 1994 to May 15, 1995 & $24.9 \pm 4.2$ & $24.6 \pm 3.3$ \\
May 15, 1995 to Aug. 20, 1995 & $1.1 \pm 6.1$ & $-0.6 \pm 5.4$ \\
Aug.20, 1995 to Oct. 20, 1996 & $16.6 \pm 2.5$ & $17.4 \pm 2.4$ \\
Oct. 1, 1994 to Oct. 20, 1996 & $16.2 \pm 1.9$ & $17.5 \pm 1.8$ \\
\hline
\end{tabular}

any confidence. Given the annual temperature and precipitation extremes at these high altitude sites, it is not surprising that annual variation is important.

Within uncertainties, the random walk noise determined from 2 years of GPS data $\left(0-4.7 \mathrm{~mm} / \mathrm{V}_{\mathrm{yr}}\right)$ is equivalent to estimates based on 11 years of two-color EDM data (1.3 $2.5 \mathrm{~mm} / \sqrt{\mathrm{yr}}$ ). Although a longer GPS time series is clearly required to improve the estimate, these preliminary results are consistent with, but do not prove, a common source for the random walk error, e.g., monument noise. In the subsequent discussion we assume that the random walk noise is the same for both systems and primarily reflects monument instability. We use the EDM estimate of 2.5 $\mathrm{mm} / \sqrt{ } \mathrm{yr}$ for both systems, as it is better determined and is intermediate between the range of acceptable values from GPS. This is equivalent to assuming that the GPS monuments are no better or worse than the EDM monuments.

Having established the white $(3.0 \mathrm{~mm})$ and random walk $(2.5 \mathrm{~mm} / \sqrt{\mathrm{yr}})$ noise charactersitics of the GPS length time series, we are now in a position to calculate velocities with realistic enrors for comparison to two-color EDM. Table 1 compares rates and errors for the two systems for various time periods reflecting different deformation episodes (see next paragraph) using the appropriate white and random walk noise components in their covariance matrices. The resulting rates and errors are very similar, even though EDM is a factor of 3 more precise in terms of white (instrumental) noise. Had we used only white noise, the rate error would be much smaller for two-color EDM and marginally smaller for GPS. Since random walk noise is much larger than white noise for two-color EDM, the rate uncertainty is dominated by random walk noise [Johnson and Agnew, 1995]. In contrast, for GPS the white noise component is larger and the rate uncertainty is dominated by white noise, except for long time spans, depending on the ratio of white to random walk noise and the sampling frequency. The cross-over period in years, $P_{0}$, where the error contributions are equal, is given by:

$$
P_{0}=\frac{2 \pi \sigma_{w}}{\sigma_{r w} \sqrt{f_{s}}}
$$

where $f_{S}$ is the sampling frequency in $\mathrm{yr}^{-1}$, and $\sigma_{m}$ and $\sigma_{w}$ are the random walk and white noise sigmas in $\mathrm{mm}$ and $\mathrm{mm} / \sqrt{\mathrm{yr}}$, respectively [Langbein and Johnson, 1997]. Using values appropriate for GPS and assuming 250 samples per year, the crossover period is about 6 months. For periods $<6$ months, the rate uncertainty will mainly reflect the white noise component. For periods longer than
6 months, the random walk component will increasingly dominate. The corresponding period for two-color EDM is about 3 months.

Both the GPS and two-color EDM data suggest a slowdown or "pause" in the rate of deformation between early May and mid-August 1995 (Figures 7 and 8). The ability of the two systems to measure deformation over different time periods is compared in Table 1, listing rates of baseline extension from each system before, during, and after the pause. During the 3.5 month pause, deformation decreased from $25 \mathrm{~mm} / \mathrm{yr}$ to nearly zero. Comparison of the rate for this 3.5 month interval with the background rates before and after indicates that the slowdown is significant at better than a $95 \%$ level of confidence for either technique. Since both systems observed the pause, it is almost certainly real, though not necessarily volcanic in origin. We are not aware of corresponding changes in other geophysical parameters.

The noise values derived above allow us to assess the time needed to detect a deformation rate with a certain confidence level. For example, suppose we wish to detect a deformation rate of $25 \mathrm{~mm} / \mathrm{yr}$ at the $3 \sigma$ confidence level ( $1 \sigma$ error equal to or better than $8 \mathrm{~mm} / \mathrm{yr}$ ). For GPS, the time required is approximately 3 months, while for twocolor EDM, the corresponding interval is 2 months. For any time span less than the cross-over period, the better white noise performance of the two-color EDM system can be exploited. For longer time spans, the two systems perform similarly - each is limited by monument noise, common to both systems. For the 2 year time span shown in Table 1, each system has a rate error of about $2 \mathrm{~mm} / \mathrm{yr}$.

Since rate errors for GPS over short periods are dominated by white noise, reduction of random walk noise by construction of better monuments would have only a marginal effect on rate errors for periods of interest to general volcano monitoring ( $<1$ year) and essentially no effect on velocity errors for critical short term volcanic events ( $<6$ months). Thus the monument designs for the Long Valley GPS sites are probably adequate, given current white noise limitations.

Table 2 shows the effect of different assumptions concerning monument noise when velocities are computed for longer time spans, using coordinate velocities averaged over the 2.5 years of available data (CASA) or 2.0 years (KRAKATAU). We compare the case of velocity enrors computed assuming only white noise to the case where random walk velocity error is added in quadrature to the white noise velocity error. For simplicity we assume the white noise velocity error is adequately represented by the uncertainty from the least squares fit (e.g., Figure 5). We further assume that the value of random walk noise derived

Table 2. Errors for ITRF-94 Coordinate Velocities for CASA and KRAKATAU for White and White+Random Walk Noise Model

\begin{tabular}{lcccc}
\hline & \multicolumn{2}{c}{ CASA (2.5 years) } & \multicolumn{2}{c}{ KRAK. (2.0 years) } \\
& White & White+Random & White & White+Random \\
\hline North & \pm 0.2 & \pm 1.2 & \pm 0.3 & \pm 1.3 \\
East & \pm 0.4 & \pm 1.2 & \pm 0.7 & \pm 1.5 \\
Vertical & \pm 1.0 & \pm 1.5 & \pm 1.7 & \pm 2.1 \\
\hline
\end{tabular}

All values in millimeters per year. 
for a single monument $(1.8 \mathrm{~mm} / \sqrt{ } / \mathrm{yr})$ applies equally to both sites and to all coordinates. Addition of the monument noise term over these time spans increases the velocily error estimates significantly for the north and east components, but in all cases the higher error is no more than $1.5 \mathrm{~mm} / \mathrm{yr}$. Addition of the monument noise term has only a marginal affect on the vertical component error, reflecting the latter's higher level of white noise.

\section{Estimating Source Location}

It is important to be able to estimate the source of volcanic deformation. This source may represent a shallow dike, a deeper magma chamber, the location of gas expansion due to exsolution of volatiles from rising, depressurizing magma, or even the locus of hydrothermal activity. Typically, data from numerous geodetic points are required to determine source location accurately, even for simplified point source models, and multiple sources may be present. Also, sources may evolve with time, so it is useful to be able to estimate source constraints over relatively short periods. Langbein et al. [1995a] performed a joint inversion of leveling and two-color EDM data spanning several years and inferred a dike, a deeper source, and a shallower elliptical source, the latter with long axis vertical and centroid at $5.5-7.0 \mathrm{~km}$ depth beneath the west side of the resurgent dome. This depth is shallower than the depth range of magma from seismological evidence, 7$11 \mathrm{~km}$ [Steck and Prothero, 1994; Sanders et al., 1995; Sanders and Nixon, 1995].
As few as two GPS sites can provide an estimate of the three-dimensional location of a simple point source [Mogi, 1958]. Additional stations can constrain multiple deformation sources, especially if all three velocity components are used. While our two GPS stations do not add significant new capability to the source estimation problem at Long Valley owing to the wealth of other data available, two or three GPS stations could be very important at many other currently unmonitored volcanoes. The ability of even two stations to estimate the threedimensional location of a point deformation source derives from the three-dimensional vector nature of GPS. Unfortunately this capability is often ignored, on the mistaken assumption that the quality of the vertical component from GPS is inadequate. While the vertical component derived from GPS is about a factor of 2 less precise than horizontal components, as demonstrated in this section it is adequate for our purposes. Dixon et al. [1993] showed that the GPS uplift rate at CASA was equivalent within quoted errors to that obtained by other geodetic techniques, including high-precision leveling, and that precisions were comparable for this example. Annual GPS surveys at CASA between 1988 and 1992 suggested uplift rates of $24.4 \pm 2.8 \mathrm{~mm} / \mathrm{yr}$, while nearby leveling surveys spanning the same period suggested uplift of $20 \pm 4 \mathrm{~mm} / \mathrm{yr}$ at CASA [Yamashita et al., 1992]. However in this example leveling was not performed annually, and more precise uplift rates from leveling could presumably be acquired with more frequent measurements. The main point here is that GPS-based uplift rates are sufficiently precise to

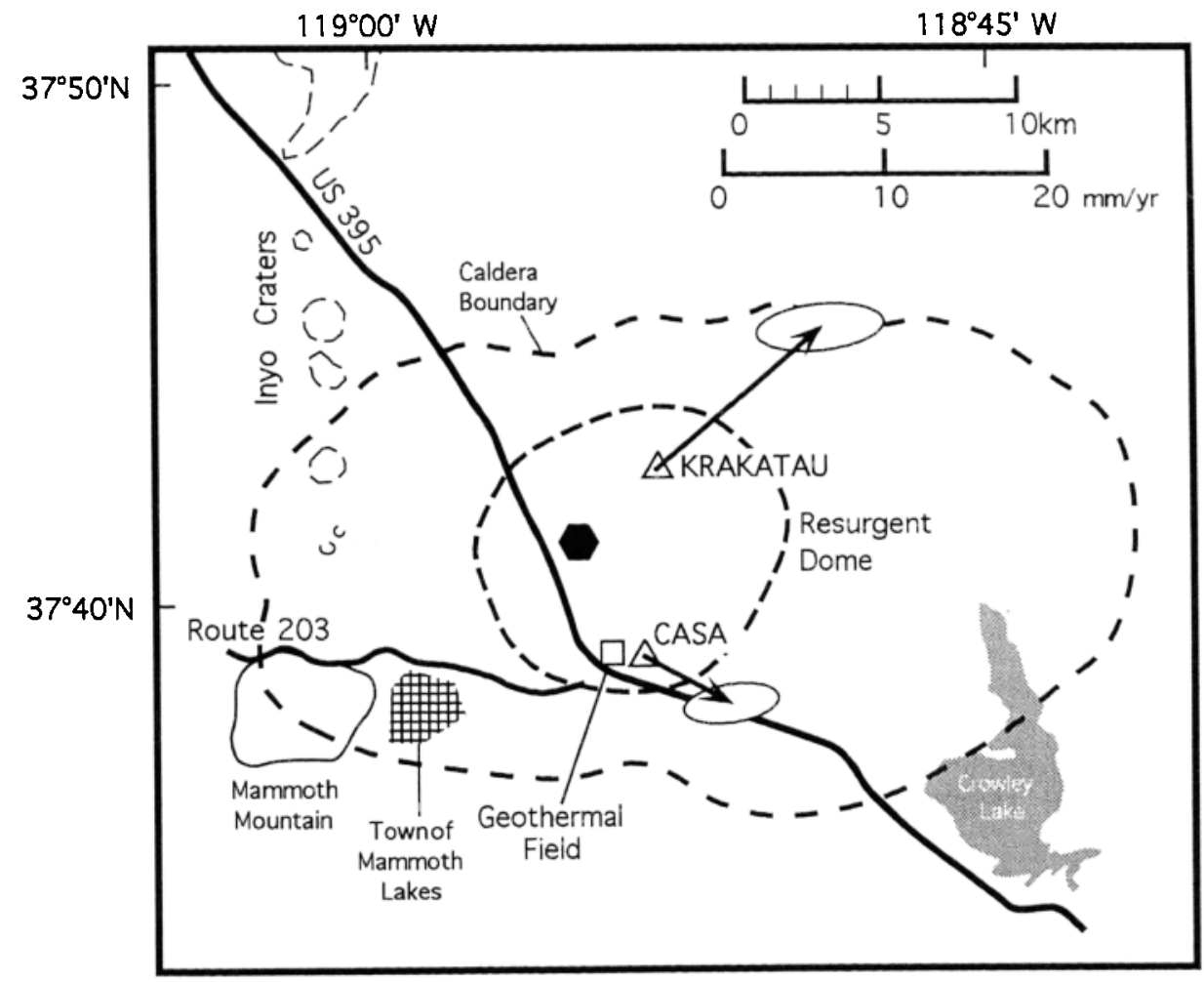

Figure 9. Horizontal components of GPS velocity for CASA and KRAKATAU relative to station CMBB on stable Sierra Nevada block (UM/POC solution for 1995; Table 3). Hexagon shows location of shallow $(5.5-7.0 \mathrm{~km})$ deformation source from two-color EDM and leveling [Langbein et al., 1995a]. Error ellipses are $95 \%$ confidence regions assuming white noise error model (Table 3 ). 
Table 3. Velocity of CASA and KRAKATAU GPS Sites Relative to Stable Sierra Nevada Block in 1995

\begin{tabular}{lrr}
\hline & \multicolumn{1}{c}{ CASA } & \multicolumn{1}{c}{ KRAKATAU } \\
\hline North $^{2}$ & $-2.9 \pm 0.5( \pm 1.9)$ & $8.7 \pm 0.6( \pm 1.9)$ \\
East $^{\mathrm{a}}$ & $5.4 \pm 1.1( \pm 2.1)$ & $10.4 \pm 1.5( \pm 2.3)$ \\
Vertical $^{\mathrm{b}}$ & $10.0 \pm 2.3( \pm 2.9)$ & $14.6 \pm 3.2( \pm 3.7)$ \\
\hline
\end{tabular}

All values in millimeters per year. First error listed assumes white noise only. Values in parentheses assume white + random walk noise (see text).

${ }^{a}$ Defined by motion of these sites between January 1 and December 31, 1995, relative to station CMBB (Figure 9).

b Defined by motion of these sites between January 1 and December 31, 1995, relative to Earth center of mass (Figure 5).

constitute a reasonable alternative to conventional approaches.

Figure 9 shows the horizontal deformation at CASA and KRAKATAU based on the UM/POC results for 1995 . We chose this arbitrary period to illustrate that useful information on volcanic deformation source can be obtained with GPS in a relatively short time. To see motion of the sites with respect to the stable Sierra Nevada block, we plot the baseline results for CASA and KRAKATAU relative to site CMBB (Table 3), located $138 \mathrm{~km}$ to the west-northwest near the center of the Sierra Nevada block. CMBB data are courtesy of the BARD network [Romanowicz et al., 1994]. We assume there is no significant deformation between our sites and the central Sierra Nevada block, other than that due to volcanic deformation in Long Valley. For comparison, we also show the surface projection of the shallow $(5.5-7.0 \mathrm{~km})$ deformation source beneath the resurgent dome defined in the model of Langbein et al. [1995a], which also included a deeper deformation source southwest of CASA and a dike. The horizontal velocities from the two GPS sites predict a source location (intersection of the two vectors) that is consistent with the independently derived location of the shallow source from two-color EDM and leveling.

In a similar way we can estimate the point source depth from GPS if we incorporate the vertical data From Mogi [1958], the ratio of vertical $V$ to horizontal $H$ surface displacement or velocity above a point source is just $V / H=$ $z / r$, where $z$ is the source depth and $r$ is the horizontal distance between the measurement point and the vertical projection of the source ( $a$ or $b$ in Figure 10). From the law of similar triangles, it can be seen that the source depth is just the intersection depth of the two surface velocity vectors extrapolated downward. For noisy data or non point source deformation, this is equivalent to the depth of closest approach of the downward extrapolated vectors. For the simplified case of two stations, A and B, on opposite sides of the deforming region, separated by a horizontal length $L$ and height $Z$, the depth $Z$ of the point source beneath the higher station $A$ is:

$$
Z=\left[\frac{L+Z \tan \beta}{(\tan \alpha+\tan \beta)}\right]
$$

where $\alpha$ and $\beta$ are the angles from vertical of the velocity vectors for stations $A$ and $B$, which depend only on the ratio of horizontal to vertical velocity at each site (Figure 10). For sites not on opposite sides, the vectors can be rotated to equivalent positions about the center of symmetry, calculating a new value for $L$. If we ignore the correlations between the horizontal and vertical velocity errors at each site and ignore correlations between stations, as well as any contribution from mismodeling a complex source as a point source, then the enror in the depth estimate $\sigma_{z}$ from (2) can be determined from standard propogation of errors [Bevington, 1969]:

$\sigma_{z}=\left\{\left[\frac{L+Z^{\prime} \tan \beta}{V^{A}(\tan \alpha+\tan \beta)^{2}}\right]^{2}\left(\sigma_{H^{A}}^{2}+\tan ^{2} \alpha \sigma_{V^{A}}^{2}\right)\right.$

$$
\left.+\left[\frac{Z^{\prime} \tan \alpha-L}{V^{B}(\tan \alpha+\tan \beta)^{2}}\right]^{2}\left(\sigma_{H^{B}}^{2}+\tan ^{2} \beta \sigma_{V^{B}}^{2}\right)\right\}^{1 / 2} \text { (3) }
$$

where $\sigma_{H, V}$ are the velocity errors. The velocities of CASA and KRAKATAU relative to CMBB are appropriate to use in this problem (Table 3 and Figure 9). However, we use only the horizontal relative velocities. For the vertical velocities, we use the individual station velocities relative to the center of mass of the Earth (Figure 5). CMBB has a different antenna than CASA or KRAKATAU, with different phase center variation with elevation angle. We have not corrected for this effect, hence mixing results via a relative baseline could corrupt vertical velocity estimates. Horizontal components are less affected by antenna mixing. For the values in Table 3, representing velocities for the period January 1 to December 31,1995 , and taking $L=9 \mathrm{~km}$, we obtain a source depth estimate of $5.8 \pm 1.1 \mathrm{~km}$. Including random walk noise in

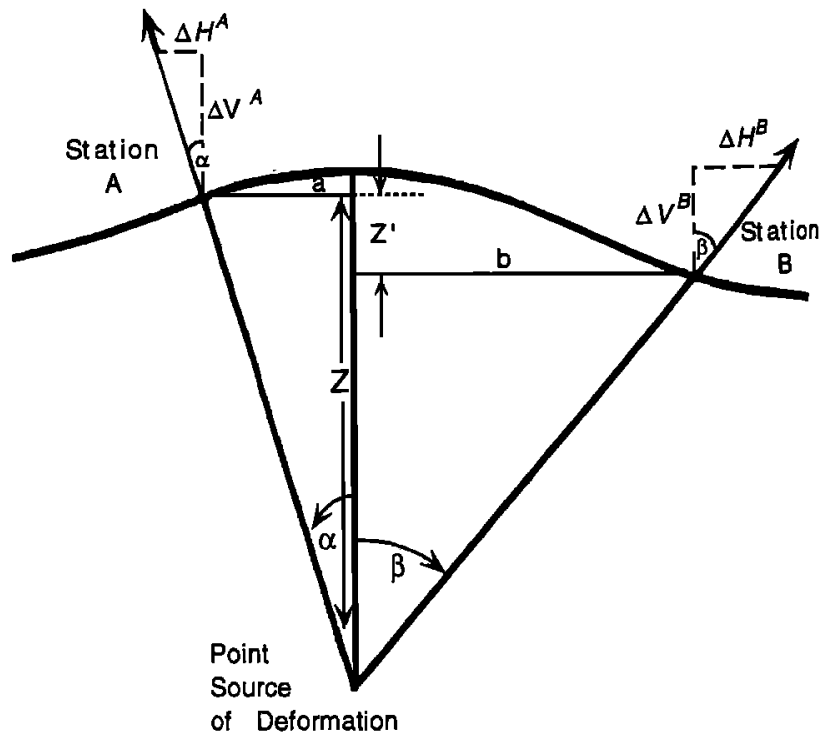

Figure 10 . Parameters used in deformation source depth estimation given two three-dimensional GPS vectors. Note that $a+b=L$ (equation (2)). 
the GPS velocity error increases the error estimate to \pm 1.6 $\mathrm{km}$. Langbein et al. [1995a] computed a centroid depth for an ellipsoidal source of $5.5-7.0 \mathrm{~km}$.

The source depth for surface deformation estimated from GPS data, as well as from two-color EDM and leveling, is near the top of the seismically defined magma chamber, 7$11 \mathrm{~km}$ [Steck and Prothero, 1994; Sanders et al., 1995; Sanders and Nixon, 1995]. Perhaps surface deformation at CASA and KRAKATAU is due mainly to accumulating gases or fluids and consequent pressure increase near the top of the magma chamber. Independent evidence for increased volatile pressure includes increased surface gas flux, as evidenced by recent tree kills from high $\mathrm{CO}_{2}$ concentrations just west of this area [Farnor et al., 1995]. Observations and theoretical models of magma degassing indicate that $\mathrm{CO}_{2}$ is a major species to degas from a wide range of silicate liquid compositions over the depth range 11 to 5 km [e.g., Giggenbach, 1996; J. Dixon and Stolper, 1995]. This is consistent with a simple model of rising magma exsolving $\mathrm{CO}_{2}$ and other volatiles which collect near the top of the magma chamber and pressurize it.

\section{Groundwater Withdrawal}

CASA is located $1.1 \mathrm{~km}$ from the well field associated with the Casa Diablo geothermal power plant (not $7 \mathrm{~km}$, as stated by Webb et al. [1995]) (Figure 1). This plant withdraws heated groundwater from relatively shallow depths and reinjects the cooled water at deeper levels. Because of the cooling effect of power generation, causing thermal contraction, and because reinjection depths are deeper than withdrawal depths, there is surface subsidence near the plant. Leveling surveys conducted in 1988 and 1992 show a narrow (<1 km radius) "cone" of subsidence centered on the well field with a maximum average subsidence rate of about $14 \mathrm{~mm} / \mathrm{yr}$ [Sorey et al., 1995, Figure 6]. However, the production rate increased from an average of $230 \mathrm{~kg} / \mathrm{s}$ in the period $1985-1990$ to $850 \mathrm{~kg} / \mathrm{s}$ in 1990-1995 [Sorey et al., 1995]. Although the connection between production rate and subsidence rate is not straightforward, it seems likely that both the subsidence rate and the affected area increased after 1990. Preliminary analysis of the 1995 leveling data confirms increased subsidence rate in the post-1990 period. The 1995 leveling data also suggest that the CASA site has subsided at about $3 \mathrm{~mm} / \mathrm{yr}$ over the last 5 years owing to groundwater pumping. This is near the noise limit of the GPS vertical velocity estimate. Horizontal effects due to groundwater pumping are likely to be the same magnitude and thus marginally significant because of higher horizontal precision. We have not attempted to account for these effects.

\section{Problems Due to Snow}

Webb et al. [1995] demonstrated that artifacts of several tens of centimeters in the vertical component of CASA's coordinates were associated with periods of deep (1-2 m) snow cover, and they removed these data from consideration when assessing the rate of volcanic deformation. Installing the antennas on taller monuments or poles would reduce this problem, althought this might increase problems with monument stability. Additionally, snow cover on the solar panels at KRAKATAU caused an extended period of power loss in January 1995 (Figure 5), but this problem did not affect CASA, which has an alternate power source. Several days of data were acquired at KRAKATAU in January after the snowfall began, reflecting battery reserve. The vertical component estimate for two of these days was apparently compted by snow on the antenna, with apparent height increasing until power loss occurred (Figure 5). The horizontal components were largely unaffected. The same behavior was observed at CASA in 1993 over a longer time span, since power was not interrupted. Installing additional batteries or using a receiver with lower power consumption would extend the operational period of the receiver during conditions of poor weather or snow-covered solar panels.

Since the GPS receivers are apparently capable of tracking satellite signals even when the antennas are covered by a thick layer of snow, in principle the depth of snow over the antenna could be estimated much as we estimate atmospheric parameters from GPS data [e.g., Dixon and Kornreich Wolf, 1990; Bevis et al., 1992], especially if atmospheric parameters were known from nearby sites. One problem is that the index of refraction varies greatly between dry versus wet snow [Tranquillo and Al Rizzo, 1993, 1994], and the full range of conditions occurs at these locations. However, modeling or calibration at several test sites may allow estimation of the mean dielectric constant for snowpack in a given region at a given time, permitting semiquantitative vertical deformation estimates during severe weather. Fortunately, the horizontal components are much less affected by snow (Figure 5b). This may help to distinguish snow-related artifacts from true volcanic deformation during real-time hazard assessment when antennas cannot be observed or cleaned.

\section{Conclusions}

1. Fully autonomous and remote GPS stations have operated at the top of the resurgent dome in Long Valley Caldera for several years, facilitating rapid and precise surface deformation monitoring in near real-time. They provide surface displacement data with precisions of about 2-3 mm/yr in the horizontal components and $3-4 \mathrm{~mm} / \mathrm{yr}$ in the vertical component averaged over a 12 month period. We suggest that similar systems are appropriate for monitoring many active volcanoes. They meet the requirements of high accuracy, moderate cost, and continuous sampling of the deformation field with autonomous operation. With further improvements and declining hardware costs, they will also become cheap enough in the next few years to enable adequate spatial sampling of the surface deformation field on many active volcanoes.

2. Although GPS length measurements are a factor of 3 noisier in day-to-day scatter than two-color EDM, the deformation recorded by both techniques is in good agreement and the rate errors for a given period are similar, e.g., about $3 \mathrm{~mm} / \mathrm{yr}$ over 12 months. The rate error for two-color EDM is limited by monument noise which can be modeled as a random walk process, while the rate error for GPS is limited mainly by instrumental noise which is 
white. Although our GPS monuments are not isolated from spurious motion of the upper colluvium, monument noise is not a significant error source for the GPS system, given the level of instrumental noise and the typical averaging times (1 year or less) likely to be useful on this and other active volcanoes.

3. Three-dimensional measurements of relative velocity from as few as two GPS sites can be used to estimate the location and depth of the deformation source assuming a simple point source model. For Long Valley Caldera, the CASA and KRAKATAU GPS data are consistent with a point source on the west side of the dome at a depth of $5.8 \pm$ $1.6 \mathrm{~km}$, in good agreement with predictions of other geodetic techniques.

4. Real-time relative positioning results with high time resolution can be obtained on site using broadcast ephemerides. For short $(<10 \mathrm{~km})$ baselines, the precision of these results differs by no more than about $1 \mathrm{~cm}$ from improved orbit solutions, even for observations as short as 3 hours.

5. Problems we have encountered at our two Long Valley sites include power interruptions and artifacts in the measured vertical component due to snow and subsidence effects in the measured displacement due to groundwater withdrawal at a nearby geothermal plant. These effects could be reduced or eliminated by adding extra batteries to span periods of bad weather or using a low-power receiver, placing antennas on higher monuments or rigid poles, and sitting GPS stations farther from pumping locations.

\section{Appendix: Data Processing Techniques}

With the exceptions noted below, our processing strategy follows procedures outlined by Dixon et al. [1993]. Briefly, we use the ionosphere-free combination of both undifferenced carrier phase and $\mathrm{P}$ code pseudo range data (weights of $1 \mathrm{~cm}$ and $3 \mathrm{~m}$, respectively) with an elevation angle cutoff of $15^{\circ}$. In the case of satellite orbit and clock estimation (UM/Quick Look time series), data are decimated to 6 minutes, receiver coordinates are estimated simultaneously with the initial position and velocity of each satellite, and parameters are related to the subsequent time evolution of the satellite orbits. These parameters include the solar radiation pressure (SRP) and yaw rate. SRP is modeled as a stochastic, Gauss-Markov process with a 4 hour correlation time, with $10 \%$ variation allowed over the specified time in the scale factors for the SRP model in $x$ and $z$ coordinates and $10^{-13} \mathrm{~km} / \mathrm{s}^{2}$ variation allowed in the $y$ bias. Yaw rate is modeled as white noise, with a priori sigma of $0.1 \%$. Other parameters and their treatments, estimated simultaneously with model constraints or fixed to modeled values, include:

Atmospheric parameters. Zenith wet troposphere delay at each ground station is estimated at each 6 minute epoch, assuming a random walk model with $1 \mathrm{~cm}^{2} / \mathrm{hr}$ variance [Dixon et al., 1991]. A standard dry delay is assumed based on station elevation and a standard atmosphere model;

Clock parameters. Station and satellite clock offsets from a reference clock, usually the H MASER at either Goldstone, California (GOLD), or Algonquin Park, Ontario (ALGO), are estimated at each epoch assuming a white noise model with a priori sigma of $1 \mathrm{~s}$;
Carrier phase cycle ambiguities. These are estimated as real numbers with a priori sigmas of $1 \mathrm{~ms}$;

Earth orientation parameters (EOP). These are estimated, except UT1-UTC, which is fixed to values given by the International Earth Rotation Service (predictions, rather than actual values, are used since the latter lag real time by several weeks). A priori sigmas are $100 \mathrm{~s} / \mathrm{d}$ for UT1-UTC rate, $5 \mathrm{~m}$ for $X$ and $Y$ pole position and $1 \mathrm{~m} / \mathrm{d}$ for $\mathrm{X}$ and $\mathrm{Y}$ pole rate.

Tides. Solid earth tide, pole tide, Love number variation at the $\mathrm{K} 1$ frequency and ocean tidal loading are modeled, not estimated.

For the UM/POC time series, the processing strategy is similar, except that 5 minute data decimation is used to match the satellite orbit and clock time series provided by JPL, and satellite orbits, satellite clocks, and EOP are not estimated [Zumberge et al., 1997]. For time series employing broadcast ephemerides (Figure 6 only), one site is fixed and the position of the other is estimated along with carrier phase ambiguities and station and satellite clocks. The zenith wet troposphere delays are modeled rather than estimated, because of their high correlation on this short baseline.

\section{Orbits and Reference Frames}

Several groups within the IGS currently obtain data from a global network of GPS tracking sites, compute precise GPS satellite ephemerides, and make them available to users after a few days or weeks. Slightly less accurate data are available more rapidly. The use of these orbit products is now widespread for routine analysis of GPS data, as it relieves individual users of the burden of computationally intensive orbit calculations and improves the speed and, in some cases, the precision of GPS data analysis. The improved precision reflects the fact that IGS orbits are based on a large global network of stations, the raw data for which an individual user might not be able to handle on a small computer.

One disadvantage of using previously determined orbit estimates is that the individual user loses flexibility in the choice of reference frame. Orbits are generally computed in a given reference frame which the user then "imports," potentially corrupting site position/velocity estimates if a user compares results to other data in a different reference frame and does not make the necessary corrections. This may involve extensive and time-consuming reanalysis. When using standard orbit products, we observed offsets up to several centimeters in the "absolute" coordinates of sites in the southern hemisphere for time series spanning January 1, 1995, when IGS orbit products were updated from ITRF-92 to ITRF-93. Northern hemisphere offsets were much smaller, perhaps reflecting the fact that the northern hemisphere was better defined in the ITRF-92 frame compared to the southern hemisphere. Reference frame effects tend to cancel on short relative position baselines, thus if proximal stations are available, as they are in California (e.g., Figure 9), these concerns are minor. If proximal stations are not available, velocity estimates using absolute coordinates for periods spanning such a reference frame break will be corrupted. This is important for volcano monitoring, where nearby reference sites may not be available and rapid but accurate characterization of time-variable deformation is critical. 
With this in mind, our orbit estimation strategy uses the so-called "no-fiducial approach" of Heflin et al. [1992] and Blewitt et al. [1992], where the a priori positions of all sites are loosely constrained in the analysis and allowed to adjust to new values based on the data. Site positions and velocities are subsequently transformed into a stable reference frame (in our case, ITRF-94) based on data from a subset $(20-25)$ of tracking sites whose positions are defined in ITRF-94. Both the UM/POC and UM/Quick Look time series are based on this procedure and are in the ITRF-94 reference frame. The 8 days of data representing the third time series are in the World Geodetic System (WGS) 84 reference frame, the frame used for the broadcast ephemerides. For analyses reported here, a priori constraints are $\pm 10 \mathrm{~m}$ for eight well-located tracking sites and $\pm 1 \mathrm{~km}$ for all other sites, including other tracking sites and volcano sites. The transformation is accomplished in several steps, similar to those described by vanDam et al. [1994]. Future reference frame updates are easily incorporated by retransforming the data, which is much less cumbersome than full reanalysis. The exact distribution and number of tracking sites are not critical, as long as sites are globally distributed. We have developed an algorithm that automatically selects 20-25 optimal sites from the ensemble of ITRF sites available on a given day based on geographic distribution and data availability.

The no-fiducial approach is readily implemented when satellite orbits are estimated (e.g., UM/Quick Look time series). However, if precise orbits are used, care must be used in the choice of orbit products. Since early 1995, JPL has supplied reference-frame free orbit data compatible with the no-fiducial approach, and these are used in our analyses. At this writing, limited reference-frame-free orbits are also available for 1994, but some gaps exist. Where necessary, we supplement these data with our own time series (UM/Quick Look series with orbit estimation) in order to define a continuous time series of station velocities in a consistent reference frame. Since the difference between the two time series is negligible (Figure 4), mixing them for limited periods in 1994 has little effect on our results.

\footnotetext{
Acknowledgments. We thank Grant Marshall and Mark Smith for assistance with installing the GPS stations and Stuart Wilkinson for acquisition of the two-color EDM data and periodic maintenance of GPS receivers. THD thanks Bob King for suggesting the use of time averages for comparison of GPS and two-color EDM, and Jackie Dixon for discussions about the importance of magmatic volatiles. Hadley Johnson, Kristy Tiampo, and Bob King provided thoughtful reviews which greatly improved the paper. Many of the figures in this paper were produced with "GMT" software [Wessel and Smith. 1995] Mention of commercial products in this paper is for information only and does not constitute an endorsement. This work was supported by NASA's "Dynamics of the Solid Earth" Program and the US Geological Survey.
}

\section{References}

Argus, D., and R. Gordon, No net rotation model of current plate velocities incorporating plate motion model NUVEL1, Geophys. Res. Lett., 18, 2039-2042, 1991.

Bevington, P. R., Data Reduction and Error Analyses for the Physical Sciences, 336p., McGraw-Hill, New York, 1969.

Bevis, M., S. Businger, T. Herring, C. Rocken, R. Anthes, and R. Ware, GPS meteorology: remote sensing of atmospheric water vapor using the Global Positioning System, J. Geophys. Res., 97, 15,787-15,801, 1992.

Blewitt, G., M. B. Heflin, F. H. Webb, U. J. Lindqwister, R. P. Malla, Global coordinates with centimeter accuracy in the International Terrestrial Reference Frame using GPS, Geophys. Res. Lett., 19, 853-856, 1992.

Boucher, C., Z. Altamimi, M. Feissel, and P. Sillard, Results and analysis of the ITRF94, $191 \mathrm{pp}$., Tech. Note 20, Int. Earth Rotation Serv., 1996.

Delaney, P. T., A. Miklius, T. Arnadottir, A. T. Okamura, and M. K. Sato, Motion of Kilauea volcano during sustained eruption from the Puu Oo and Kupaianaha vents, 1982-1991, J. Geophys. Res., 98, 17,801-17,820, 1993.

DeMets, C., R. Gordon, D. Argus, S. Stein, Effect of recent revisions to the geomagnetic time scale on estimates of current plate motion, Geophys. Res. Lett., 21, 2191-2194, 1994.

Denlinger, R. P., F. S. Riley, J. K. Boling, and M. C. Carpenter, Deformation of Long Valley Caldera between August 1982 and August 1983, J. Geophys. Res., 90, 11199-11209, 1985.

Dixon, J. E., and E. M. Stolper, An experimental study of water and carbon dioxide solubilities in mid-ocean ridge basaltic liquids,. II, Applications to degassing, J. Petrol. 36, 16331646, 1995.

Dixon, T. H., and S. Kornreich Wolf, Some tests of wet tropospheric calibration for the CASA Uno Global Positioning System experiment, Geophy-. Res. Lett., 17, 203-206, 1990.

Dixon, T. H., G. Gonzalez, S. Lichten, and E. Katsigris, First epoch geodetic measurements with the Global Positioning System across the northern Caribbean plate boundary zone, J. Geophys. Res., 96, 2397-2415, 1991.

Dixon, T. H., M. Bursik, S. Kornreich Wolf, M. Heflin, F. Webb, F. Farina, S. Robaudo, Constraints on deformation of the resurgent dome, Long Valley caldera, California from space geodesy, in Space Geodesy and Geodynamics, Geodyn. Ser., vol. 23, edited by D. Smith and D. Turcotte, pp. 193214, AGU, Washington, D.C., 1993.

Dixon, T. H., F. Farina, A. Mao, F. Webb, M. Bursik, R. Stein, and G. Marshall, GPS monitoring data for active volcanos available on Internet, Eos Trans. AGU, 76, 2, 1995.

Dvorak, J., A complete earthquake cycle along the south flank of Kilauea volcano, Hawaii, J. Geophys. Res., 98, 49935001, 1993.

Dzurisin, D., J. Savage, and R. Foumier, Recent crustal subsidence at Yellowstone caldera, Bull. Volcanol., 52, 247 $270,1990$.

Farrar, C. D., M. L. Sorey, W. C. Evans, J. F. Howle, B. D. Kerr, B. M. Kennedy, C. Y. King, and J. R. Southon, Forestkilling diffuse $\mathrm{CO} 2$ emission at Mammoth Mountain as a sign of magmatic unrest, Nature, 376, 675-678, 1995.

Giggenbach, W. F., Chemical composition of volcanic gases, in Monitoring and Mitigation of Volcano Hazards, edited by R. Scarpa and R. I. Tilling, pp. 221-256, Springer-Verlag, New York, 1996.

Heflin, M. Global geodesy using GPS without fiducial sites, Geophys. Res. Lett., 19, 131-134, 1992.

Johnson, H. O., and D. C. Agnew, Monument motion and Measurements of crustal velocities, Geophys. Res. Lett., 22, 2905-2908, 1995.

Langbein, J., Deformation of the Long Valley Caldera, eastern California from mid-1983 to mid-1988: measurements using a two-color geodimeter, J. Geophys. Res., 94, 3833-3849, 1989.

Langbein, J., and H. Johnson, Correlated errors in geodetic time series: Implications for time-dependent deformation, $J$. Geophys. Res., 102, 591-603, 1997.

Langbein, J. O., D. P. Hill, T. N. Parker, and S. K. Wilkinson, 
An episode of re-inflation of the Long Valley Caldera, eastern California; 1989-1991, J. Geophys. Res., 98, 15,851-15,870, 1993.

Langbein, J. O., D. Dzurisin, G. Marshall, R. Stein, and J. Rundle, Shallow and peripheral volcanic sources of inflation revealed by modeling two-color geodimeter and leveling data from Long Valley caldera, California, 1988-1992, J. Geophys. Res., 100, 12,487-12495, 1995a.

Langbein, J. O., F. Wyatt, H. Johnson, D. Hamann, and P. Zimmer, Improved stability of a deeply anchored geodetic monument for deformation monitoring, Geophys. Res. Lett., 22, 3533-3536, $1995 \mathrm{~b}$.

Linde, A., K. Agustsson, I. S. Sacks, and R. Stefansson, Mechanism of the 1991 eruption of Hekla from continuous borehole strain monitoring, Nature, 365, 737-740, 1993.

Marshall, G. A., J. Langbein, R. S. Stein, M. Lisowski, and J. Svarc, Inflation of Long Valley Caldera, California, Basin and Range strain, and possible Mono Craters dike inflation from 1990-1994 GPS surveys, Geophys. Res. Lett., in press, 1997.

Mogi, K., Relations between the eruptions of various volcanoes and the deformations of the ground surfaces around them, Bull. Earthquake Res. Inst., Univ. Tokyo, 36, 99-134, 1958.

Murray, T. L., J. W. Kleinman, E. Y. Iwatsubo, and D. Dzurisin, Establishment of a permanent radio-telemetered GPS network on Augustine Volcano, Cook Inlet, Alaska (abstract), Eos: Trans. AGU, 73(43), Fall Meet. Suppl., 124, 1992.

Niell, A. E., P. Elфsegui, J. L. Davis, I. I. Shapiro, R. T. K. Jaldehag, J. M. Johansson, Reduction of signal multipath effects on GPS estimates of site position, Eos Trans. AGU., 75(44), Fall Meet. Suppl., 171, 1994.

Owen, S., P. Segall, J. Freymueller, A. Miklius, R. Denlinger, T. Annadotir, M. Sako, and R. Burgmann, Rapid deformation of the south flank of Kilauea volcano, Hawaii, Science, 267 , 1328-1332, 1995.

Romanowicz, B., D. Neuhauser, B. Bogaert and D. Oppenheimer, Accessing northern California earthquake data via Internet, Eos: Trans AG U., 75, 257, 259, 2601994.

Rundle, J. B., and J. H. Whitcomb, A model for deformation in Long Valley, California, 1980-1983, J. Geophys. Res., 89, 9371-9380, 1984.

Sanders, C. O., and L. D. Nixon, S wave attenuation structure in Long Valley caldera, California from three-component $\mathbf{S}$ to $\mathrm{P}$ amplitude ratio data, $J$. Geophys. Res., 100, 12,395$12,404,1995$.

Sanders, C. O., S. C. Ponko, L. D. Nixon, and E. A. Schwartz, Seismological evidence for magmatic and hydrothermal structure in Long Valley caldera from local earthquake attenuation and velocity tomography, J. Geophys. Res., 100, 8311-8326, 1995.

Savage, J. C., Principal component analysis of geodetically measured deformation in Long Valley Caldera, eastern California, 1983-1987, J. Geophys. Res., 93, 13,29713,305, 1988.

Savage, J.C., and W.H. Prescott, Precision of geodolite distance measurements for determining fault movements, $J$. Geophys. Res., 78, 6001-6008, 1973.

Shimada, S., Y. Fujinawa, S. Sekiguchi, S. Ohmi, T. Eguchi, and Y. Okada, Detection of a volcanic fracture using GPS, Nature, 343, 631-633, 1990.

Slater, L.E, and G.R. Huggett, A multi-wavelength distance- measuring instrument for geophysical experiments, $J$. Geophys. Res., 81, 6299-6304, 1976.

Sorey, M. L., C. D. Farrar, G. Marshall, J. Howle, Effects of geothermal development on deformation in Long Valley caldera, eastern California, 1985-1994, J. Geophys. Res., $100,12,475-12,486,1995$.

Steck, L. K., and W. A. Prothero, Crustal structure beneath Long Valley caldera from modeling of teleseismic P-wave polarizations and Ps converted waves, J. Geophys. Res., 99, 6881-6898, 1994.

Thatcher, W., Precursers to eruption, Nature, 343, 590-591, 1990.

Tranquillo, J. M., and H. M. Al Rizzo, Theoretical and experimental evaluation of precise relative positioning during periods of snowfall precipitation using the Global Positioning System, Man Geod., 18, 362-379, 1993.

Tranquillo, J. M., and H. M. Al Rizzo, Range errors in Global Positioning System during ice cloud and snowfall periods, IEEE Trans. Antennas Propag. , 42, 157-165, 1994.

vanDam, T., G. Blewitt, and M. Heflin, Atmospheric pressure loading effects on Global Positioning System coordinate determination, J. Geophys. Res., 99, 23,939-23,951, 1994.

Vasco, D., L. Johnson, and N. Goldstein, Using surface displacement and strain observations to determine deformation at depth, with an application to Long Valley caldera, California, J. Geophys. Res., 93, 3232-3242, 1988.

Webb, F., M. Bursik, T. Dixon, F. Farina, and G. Marshall, R. Stein, G. Marshall, Inflation of Long Valley caldera from one year of continuous GPS measurements, Geophys. Res. Lett., 22, 195-198, 1995.

Wessel, P. and W. H. F. Smith, New version of generic mapping tools released, EOS: Trans. Am. Geophys. U., 76, 329. 1995.

Wyatt, F., Displacement of surface monuments: Vertical motion, J. Geophys. Res., 94, 1655-1664, 1989.

Yamashita, K. M., J W. Kleinman, E. Y. Iwatsubo, J. W. Ewart, D. Dzurisin, J. B. Rundle, and R. S. Stein, Results of 1992 leveling survey at Long Valley caldera, California (abstract), Eos: Trans. AGU, 73, (43), 347, Fall Meet. Suppl., 1992.

Yang, X., P. Davis, P. Delaney, and A. Okamura, Geodetic analysis of dike intrusion and motion of the magma reservoir beneath the summit of Kilauea volcano, Hawaii: 1970-1985, J. Geophys. Res., 97, 3305-3324, 1992.

Zumberge, J. F., M. Heflin, D. Jefferson, M. Watkins, F. Webb, Precise point positioning for efficient and robust analysis of GPS data from large networks, J. Geophys. Res., 102, 5005-5017, 1997.

M. Bursik, Department of Geology, State University of New York, Buffalo, NY 14260.

T.H. Dixon and A. Mao, Rosenstiel School of Marine and Atmospheric Science, University of Miami, 4600 Rickenbacker Causeway, Miami FL 33149 (e-mail: tim@corsica.rsmas.miami.edu).

M. Heflin and F. Webb, Jet Propulsion Laboratory, California Institute of Technology, MS 238-600, 4800 Oak Grove Dr., Pasadena, CA 91109-8099.

J. Langbein and R. Stein, U.S. Geological Survey, MS 977, 345 Middlefield Rd., Menlo Park, CA 94025.

(Received June 12, 1996; revised December 6, 1996;

accepted December 11, 1996.) 